OPEN ACCESS

Edited by:

Michael Costigan,

Boston Children's Hospital, Harvard Medical School, United States

Reviewed by:

Nasiara Karim,

University of Malakand, Pakistan Lorenzo Di Cesare Mannelli,

University of Florence, Italy

${ }^{*}$ Correspondence:

Nara Lins Meira Quintão nara.quintao@univali.br; narafarmaco@yahoo.com.br

Specialty section: This article was submitted to

Neuropharmacology,

a section of the journa

Frontiers in Neuroscience

Received: 29 May 2019 Accepted: 14 August 2019

Published: 28 August 2019

Citation:

Quintão NLM, Santin JR, Stoeberl LC, Corrêa TP, Melato $J$ and

Costa $R$ (2019) Pharmacological Treatment of Chemotherapy-Induced Neuropathic Pain: PPARy Agonists as a Promising Tool.

Front. Neurosci. 13:907. doi: 10.3389/fnins.2019.00907

\section{Pharmacological Treatment of Chemotherapy-Induced Neuropathic Pain: PPAR $\gamma$ Agonists as a Promising Tool}

\author{
Nara Lins Meira Quintão ${ }^{*}$, José Roberto Santin ${ }^{1}$, Luis Carlos Stoeberl', \\ Thiago Patrício Corrêa ${ }^{1}$, Jéssica Melato ${ }^{1}$ and Robson Costa ${ }^{2,3}$ \\ ${ }^{1}$ School of Heath Science, Universidade do Vale do Itajaí, Itajaí, Brazil, ${ }^{2}$ School of Pharmacy, Federal University of Rio \\ de Janeiro, Rio de Janeiro, Brazil, ${ }^{3}$ Wolfson Centre for Age-Related Diseases, King's College London, London, \\ United Kingdom
}

Chemotherapy-induced neuropathic pain (CINP) is one of the most severe side effects of anticancer agents, such as platinum- and taxanes-derived drugs (oxaliplatin, cisplatin, carboplatin and paclitaxel). CINP may even be a factor of interruption of treatment and consequently increasing the risk of death. Besides that, it is important to take into consideration that the incidence of cancer is increasing worldwide, including colorectal, gastric, lung, cervical, ovary and breast cancers, all treated with the aforementioned drugs, justifying the concern of the medical community about the patient's quality of life. Several physiopathological mechanisms have already been described for CINP, such as changes in axonal transport, mitochondrial damage, increased ion channel activity and inflammation in the central nervous system (CNS). Another less frequent event that may occur after chemotherapy, particularly under oxaliplatin treatment, is the central neurotoxicity leading to disorders such as mental confusion, catatonia, hyporeflexia, etc. To date, no pharmacological therapy has shown satisfactory effect in these cases. In this scenario, duloxetine is the only drug currently in clinical use. Peroxisome proliferator-activated receptors (PPARs) belong to the class of nuclear receptors and are present in several tissues, mainly participating in lipid and glucose metabolism and inflammatory response. There are three PPAR isoforms: $\alpha, \beta / \delta$ and $\gamma$. PPAR $\gamma$, the protagonist of this review, is expressed in adipose tissue, large intestine, spleen and neutrophils. This subtype also plays important role in energy balance, lipid biosynthesis and adipogenesis. The effects of PPAR $\gamma$ agonists, known for their positive activity on type II diabetes mellitus, have been explored and present promising effects in the control of neuropathic pain, including CINP, and also cancer. This review focuses largely on the mechanisms involved in chemotherapy-induced neuropathy and the effects of the activation of PPAR $\gamma$ to treat CINP. It is the aim of this review to help understanding and developing novel CINP therapeutic strategies integrating PPARy signalling.

Keywords: chemotherapy, platinum, taxane, nuclear receptor, neuropathy, chronic pain, side effects, quality of life 


\section{INTRODUCTION}

Cancer is in the second position in the ranking of death causes after heart diseases across the globe and despite the huge efforts to implement novel chemotherapy strategies, the disease remains one of the major concerns worldwide (Bray et al., 2018). In 2012, the global number of new cases of cancer was 14.1 million, and the corresponding number of deaths was 8.2 million (Torre et al., 2015). For the year of 2018, according to The International Agency for Research on Cancer (IARC), 18.1 million of new cancer cases were estimated, followed by 9.6 million of deaths (Bray et al., 2018). The growing incidence and mortality of cancer is a result of population growth and ageing, besides changes in reproductive factors and unhealthy habits associated with economic development and urbanisation (Ferlay et al., 2015).

Approximately one-half of the cancer cases and deaths occurred in Asia, followed by Europe $(23.4 \%$ of the cases and $20.3 \%$ of the deaths) and Northern America (21\% of the cases and 14.4\% of the deaths) (Bray et al., 2018; Ferlay et al., 2019). Lung, prostate and colorectal cancer were the most commonly diagnosed types of cancer among men, and lung cancer is the responsible for the greater number of deaths. The most frequent types of cancer in women were breast, colorectal and lung cancer, being breast cancer the top of five in cause of death (Bray et al., 2018).

Although the improvement of cancer survival by the aggressive treatments, new anti-cancer drugs are also responsible for serious side-effects on daily life that can last for many years. Cancer survivors suffer more from functional impairment, involving reduced mobility, than individuals without cancer history. The functional declines associated with cancer are linked to limited survival (Winters-Stone et al., 2017). Neurotoxicity to the peripheral (PNS) nervous system is an emerging side effect of cancer chemotherapy with no existing effective treatments (Brown et al., 2019). Chemotherapy-induced peripheral neurotoxicity (or neuropathy) is the most dose-limiting side effect of anti-cancer drugs, such as paclitaxel, vincristine and oxaliplatin, drugs widely used for treating several tumours. Peripheral neuropathy usually manifests as painful symptoms, characterising a neuropathic pain syndrome. However, it can progress to loss of sensory perception in the most severe cases. Additionally, motor and/or autonomic peripheral neuropathy can also occur (Brown et al., 2019). Chemotherapy-induced neuropathic pain (CINP) severally impairs the patient's quality of life and leads to dose reduction or even treatment cessation (Miltenburg and Boogerd, 2014).

Recent pre-clinical studies have shown the efficacy of activators of the peroxisome proliferator-activated receptor gamma (PPAR $\gamma)$, known as glitazones, on neuropathic pain models (Okine et al., 2019). Therefore, glitazones might become new and effective pharmacological approaches to prevent CINP. In the present review, we will address pathophysiological mechanisms of CINP, its current pharmacological treatment and the use of PPAR $\gamma$ activators as potential therapeutic tools to manage CINP.

\section{CHEMOTHERAPY}

The novel insights into the biology of cancer have been translated into improvements in clinical care at fast pace over the past 15 to 20 years. The introduction of sophisticated molecular tools, which interrogate both cancer diseases and patients, has led to a steady stream of new therapeutic interventions and altered the natural history of several solid tumours and heamatopoietic malignancies (Doroshow and Kummar, 2014).

The causes of cancer include damage and/or mutations in the cells' genetic material associated with environmental or inherited factors, leading to uncontrolled cell proliferation. For cancers with local and non-metastatic profile, surgery and radiotherapy are the primary treatments choice. However, anti-cancer drugs, mainly chemotherapy, are the choice for treating metastatic cancers, since they are able to diffuse through the body (Hanahan and Weinberg, 2011). Anticancer drugs are toxic for cancer cells and inhibit their fast proliferation; however, they are not selective and also inhibit the growth of normal cells, leading to undesirable side effects commonly observed in cancer treatment. Chemotherapy has progressed towards more effective treatments, including the combination of drugs and new approved anticancer drugs, such as platinum analogues, paclitaxel and other agents (Perez-Herrero and Fernandez-Medarde, 2015).

The development of chemotherapy drugs began in animal models in the twentieth century, but only during World War II the first reports of curative effects appeared. Advances in research and the recognition of oncology as a medical specialty allowed the creation of the first protocol to treat advanced cases of childhood leukaemia and Hodgkin's disease in the 1960s and 1970s (Devita and Chu, 2008). Figure 1 shows the timeline of the FDA approval for chemotherapies over the last seven decades. The drug combination, using doxorubicin, bleomycin, vinblastine and dacarbazine, remains nowadays as the standard treatment for the management of Hodgkin's lymphomas. At the same time, other drugs, such as methotrexate and cyclophosphamide, were included in the profile of cancer treatments (Chabner and Roberts, 2005). Chemotherapy included as adjunct to the surgical management of breast and colorectal tumours also began to spread in the same decade. With this new approach, the patient's survival drastically increased (Bonadonna et al., 1976).

In the 1980s, the use of cisplatin (first-generation platinum) was started for the treatment of testicular cancer. After a good clinical response, its use was extended to ovarian, lung, head and neck and uterine cervix tumours (Carozzi et al., 2015). The main mechanism of action of cisplatin is the formation of a DNA-cisplatin adduct, which distorts the double helix of DNA and thus changes its structure. This effect induces cell death by apoptotic and necrotic processes (Jung and Lippard, 2007). Five years after the introduction of cisplatin, carboplatin, a second-generation platinum, emerged clinically. Carboplatin differs from cisplatin by the presence of a carboxylate-type binder in its chemical structure. The greater excretion through the urine, greater solubility in water and lower reactivity confer the carboplatin less toxicity when compared to the first-generation platinum (Wheate et al., 


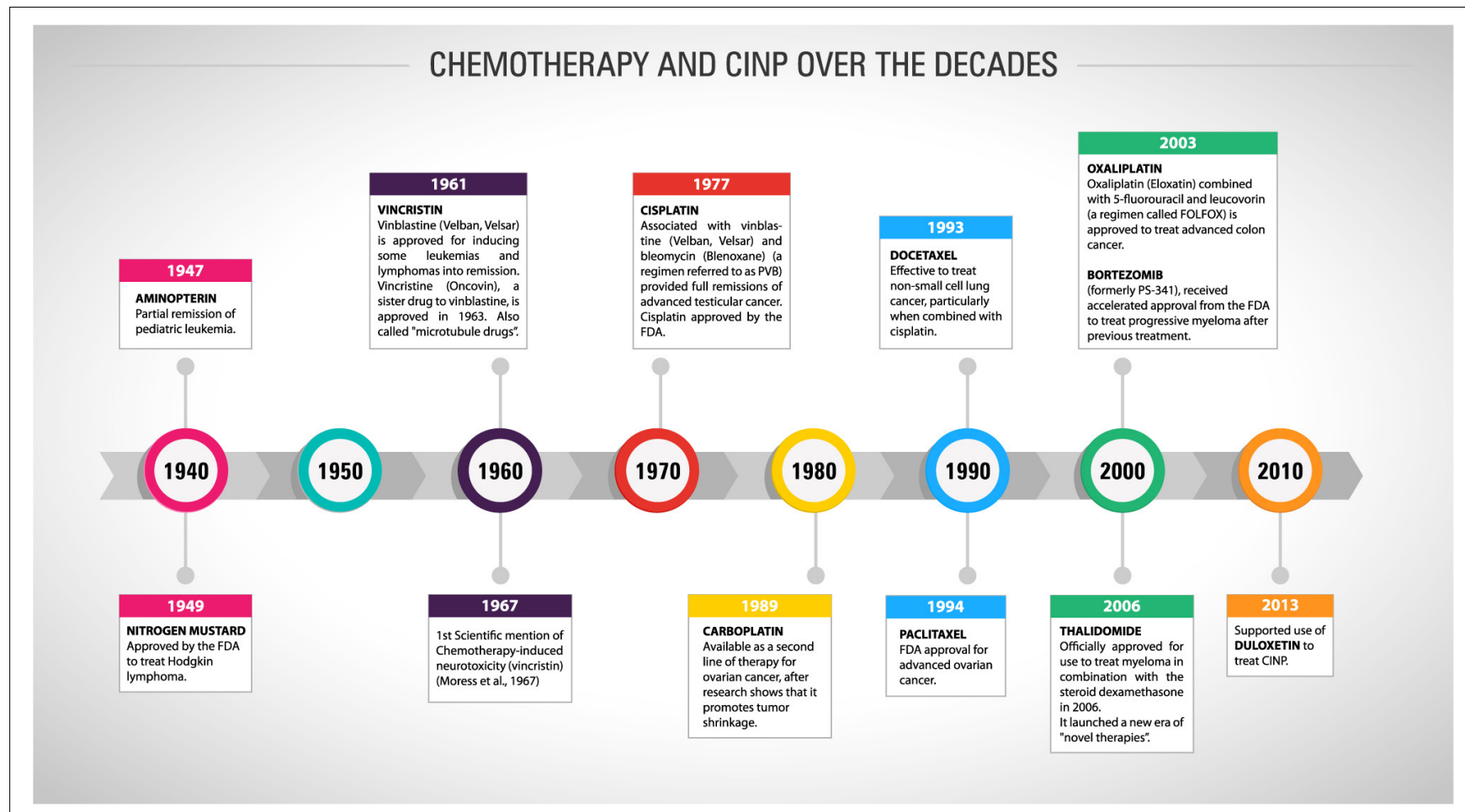

FIGURE 1 | Timeline showing the history of chemotherapy and cancer treatment and the first mention of CINP and its recommended treatment over the last eight decades.

2010). Its efficacy in relation to cisplatin is seen mainly in cases of lung carcinomas (Pasetto et al., 2006). Oxaliplatin is the third-generation platinum which differs from cisplatin by the presence of an oxalate leaving group and a $\mathrm{DACH}$ (diaminocyclohexane) linker. Oxaliplatin is effective in cisplatinresistant tumours because the DNA repair system does not recognise its adducts and is widely used in colorectal cancer (Pasetto et al., 2006). Neves and Vargas (2011) pointed to epidemiological data demonstrating a large scale of use of platinum (monotherapy or in combination with other drugs) in clinical oncology, ranging from 40 to $80 \%$ of the malignant tumours described cases.

Paclitaxel, the taxanes prototype, was firstly isolated in 1971 as part of a National Cancer Institute programme investigating a large range of plant extracts. It was initially isolated from Taxus brevifolia bark. Docetaxel, from the same class of anticancer drugs, was semi-synthetically obtained and presents higher solubility in water than paclitaxel. Taxanes are effective against breast, lung, ovarian, cervical and pancreatic cancers and Kaposi sarcoma (Weaver, 2014). The pharmacological effect of paclitaxel consists in its ligation to cytoplasm polymerised tubulins, interrupting G2 phase of cell cycle and, then, stabilising the microtubules. This interaction with tubulins also causes mitochondrial damage by opening the mitochondrial permeability transition pore, that has $\beta$-tubulin in its constitution, increasing the $\mathrm{Ca}^{2+}$ efflux and eventually apoptotic or necrosis cell death (Jordan and Wilson, 2004). This impairment does not occur exclusively in cancer cells, what reflect the numerous side effects experienced by the patients, including myelosuppression, hypersensitivity responses and, the most important, neuropathic pain (Carozzi et al., 2015).

With the best understanding of the genetic and phenotypic alterations of the tumours, the modalities of systemic treatments in oncology were expanded, being reinforced by the immunotherapy. It has been found that cancer cells in some specific types of cancer express on their surface proteins that could be used as targets for modulation and disruption of the tumour expansion process. Although cancer cells are highly genetically unstable, immunotherapy has been successfully used to manage numerous tumour types (Martin et al., 2015a). Toxicological assays that compared chemotherapy agents with immunomodulatory regimens in oncology concluded that the last has a greater safety in clinical applicability due to their well-defined targets, unlike chemotherapy agents that are less specific (Waldmann, 2003). In the current scenario, the greatest difficulty of immunotherapy is to adjust and handle enough monoclonal antibodies to reach the tumour site, so that its effect is potentiated. In addition, it is also required that the target of the monoclonal antibody should be highly specific and sufficiently expressed by the tumour cell, in addition of being directly involved with the cancer genesis (Guimaraes et al., 2008). Despite significant advances in cancer treatment with the discovery of immunotherapy, for some cancers, chemotherapy remains as gold standard treatment. 


\section{SIDE EFFECTS OF CHEMOTHERAPY}

Cytotoxic agents have narrow therapeutic indexes, with limited selectivity against cancer cells and high toxicity potential; consequently, anti-cancer drugs have limited efficacy at doses that are acceptable for most patients (Borcoman and Le Tourneau, 2016). Side effects of chemotherapy remain the major concern for both patients and clinicians despite the increase in efficacy and survival rates with the current treatments. The current approaches to counteract the side effects of chemotherapy are not completely effective, usually do not address long-term consequences or can induce other side effects (Nurgali et al., 2018).

Nausea and vomiting are the most dreaded side effects for patients who initiate anti-cancer chemotherapy. The current treatments to control acute chemotherapy-induced nausea and vomiting (CINV) are effective for most patients; however, the management of delayed CINV is more difficult to obtain (Andrews and Sanger, 2014). Mucositis is also an important side effect of anti-cancer drugs. Both oral and gastrointestinal mucositis can cause local ulceration and pain, leading to anorexia, malabsorption, weight loss, anaemia, fatigue and increased risk of sepsis. Despite many efforts of the scientific community, safe and effective treatments are still lacking to treat mucositis (Abalo et al., 2017). Other side effects of chemotherapeutic agents include hypersensitivity reactions to carboplatin in children with solid tumours; chronic subclinical skeletal muscle toxicity caused by oxaliplatin; and nephrotoxicity, ototoxicity and increased risk of cardiovascular disease in patients treated with cisplatin (Malik et al., 2016).

Central neurotoxicity induced by anticancer drugs can lead to persistent cognitive impairment, which has been associated with alterations in circulating factors and cerebrospinal fluid constituents, and occurrence of genetic polymorphisms. Additionally, peripheral neurotoxicity caused by many anti-cancer drugs, including platinum-based agents, vinca alkaloids and taxanes, can lead to neuropathic pain. These side effects can last many years after discontinuation of treatment and reduce the quality of life of cancer survivors. In addition, long term CINP is associated with depression, anxiety and insomnia. Therefore, the preventive and therapeutic strategies for CINP are an urgent need (Zhou et al., 2018).

\section{CHEMOTHERAPY-INDUCED NEUROPATHIC PAIN}

Chemotherapy-induced neuropathic pain is essentially caused by injury to the somatosensory nervous system after anticancer drug treatment, and it is one of the major causes of neuropathic pain in clinical practice (Colvin, 2019). The incidence of CINP is variable among the studies with up to 81 and $98 \%$ for paclitaxel and oxaliplatin, respectively (Hershman et al., 2011; Gilchrist et al., 2017; Gebremedhn et al., 2018; Molassiotis et al., 2019). The occurrence of CINP may change according to number of cycles and duration of treatments, drug chemical structure, age, prescription of other neurotoxic drugs and presence of predisposing conditions such as alcoholism, diabetes or pre-existing neuropathy (Argyriou et al., 2014; Kerckhove et al., 2018). Sensory symptoms usually manifest as spontaneous or evoked abnormal sensations such as paraesthesia, dysesthesias, numbness, burning, shooting or electric shock sensations, as well as allodynia or hyperalgesia evoked by mechanical or thermal stimuli. The symptoms usually affect the extremities of the upper and lower limbs ("stocking and glove" distribution) and progress to the proximal regions of the body (Miltenburg and Boogerd, 2014; Colvin, 2019).

Chemotherapy-induced neuropathic pain can manifests initially as an acute pain syndrome, with sensory symptoms arising during or just after drug administration, and progress to a chronic neuropathy after repetitive treatment cycles. Regarding the duration of sensory symptoms, acute neuropathy generally subsides between treatments, while chronic neuropathy can persist for months or years (Colvin, 2019). Indeed, $47 \%$ of patients treated with anti-cancer drugs still experience peripheral neuropathy symptoms after 6 years of treatment termination (Winters-Stone et al., 2017). Chronic pain severely impairs the quality of life of cancer patients, reminding them of time they had cancer and that the disease may return (Binder and Baron, 2016). The available pharmacotherapies for CINP are poorly effective and associated with numerous side-effects. However, the search for more effective treatments is difficult as the physiopathology of CINP involves a complex machinery (for review see, Sisignano et al., 2014). Therefore, a deep knowledge of the molecular mechanisms involved in CINP is crucial to provide new molecular mechanism-based therapies instead of simply treating symptoms.

Several pathophysiological mechanisms have been described for CINP including mitochondrial dysfunction, changes in calcium homeostasis, oxidative stress, activation of apoptotic pathways, loss of myelinated and unmyelinated fibres, activation of the immune system and increased ion channel expression and activity. Comprehensive analysis of the pathophysiological mechanisms associated with CINP have already been performed elsewhere, and readers are invited to consult these reviews (for review see, Sisignano et al., 2014; Fukuda et al., 2017; Starobova and Vetter, 2017; Trecarichi and Flatters, 2019; Zajaczkowska et al., 2019). Despite some specific neurotoxic effects, anticancer drugs have important and mutual pathophysiological mechanisms that contribute to the development of CINP. Herein, we will present a possible sequence of events connecting the common mechanisms described for CINP associated with different anticancer drugs.

Peripheral sensory neurons are vulnerable to the toxic action of anti-cancer drugs as the PNS is devoid of a complex vascular-nerve barrier, allowing the diffusion of systemicadministered drugs to the dorsal root ganglia (DRG) (Abram et al., 2006; Sapunar et al., 2012). The damage to the cellular bodies of sensory neurons leads to the degeneration of myelinated fibres (mainly) and, consequently, inflammatory process, overactivity of remaining fibres and central sensitisation (Fukuda et al., 2017). In fact, axonopathy and loss of epidermal innervation were described after the treatment with paclitaxel, vincristine or ixabepilone (Lapointe et al., 2013). 
Furthermore, peripheral and central inflammatory responses have been described as important mechanisms of pain, including paclitaxel-, vincristine- and oxaliplatin-induced neuropathic pain (Marotta et al., 2009; Ji et al., 2013; Janes et al., 2015; Makker et al., 2017; Segat et al., 2017; Costa et al., 2018; Manjavachi et al., 2019). Additionally, these drugs increase the activity of both voltage-dependent calcium (Cav) and sodium (Nav) channels, and transient receptor potential (TRP) channels in peripheral nerves (Sisignano et al., 2014). Central neuronal sensitisation, marked by phosphorylation and activation of $N$-methyl-D-aspartate (NMDA) receptor, has also been described for CINP (Pascual et al., 2010; Mihara et al., 2011; Ji et al., 2013).

Regarding the cellular mechanisms of CINP, mitochondrial damage has been reported as a key component of the damage to sensory neurons in the DRG after the treatment with different anticancer drugs. It has been widely reported that paclitaxel, vincristine and oxaliplatin cause mitochondrial dysfunction and, consequently, increased production of reactive oxygen species (ROS) in the DRG (Duggett et al., 2016, 2017; Gong et al., 2016; Vashistha et al., 2017; Khasabova et al., 2019). Chemotherapy causes impairment in cellular respiration and decreases the production of adenosine triphosphate (ATP), and promoting mitochondrial respiration and restoring mitochondrial bioenergetics has protective effect on CINP (Bennett et al., 2014; Toyama et al., 2018). Additionally, the level and activity of superoxide dismutase (SOD) and catalase, two important antioxidant enzymes, are reduced by the treatment with anti-cancer drugs generating an imbalance between oxidant and antioxidant molecules (Janes et al., 2013; Duggett et al., 2016; Khasabova et al., 2019). Together, these effects trigger cellular apoptotic pathways that lead to the degeneration of peripheral sensory fibres and related inflammatory process (Areti et al., 2014; Fukuda et al., 2017).

Once oxidative stress is a key event in the physiopathology of CINP, antioxidant strategies are believed to be effective alternatives for preventing the development of CINP. Studies with animal models have been performed in order to determinate the effect of several antioxidant agents on CINP (Carvalho et al., 2017). Notably, calmangafodipir, an antioxidant and neuroprotective agent, has shown to prevent oxaliplatin-induced neuropathic pain in a double-blinded randomised phase II clinical trial (Glimelius et al., 2018).

\section{TREATMENT OF CINP}

As mentioned before, the neurotoxicity and chronic pain induced by chemotherapy treatments are important adverse effects that must be considered, once they could compromise the cancer treatment and the post-treatment patients' quality of life. The first study mentioning neuropathic pain in cancer-patients dates from 1967 (Figure 1), where three case reports were presented with necropsy findings linking the neurological symptoms with vincristine neurotoxicity (Moress et al., 1967). Since then, as presented in Figure 2, the number of papers has grown year by year focussing on both the pathophysiological mechanisms of CINP and new treatments (Figure 2A). Most of publications involve regular articles (Figure 2B) and the great majority mention taxanes, followed by platinum drugs (Figure 2C).

Despite the growing search for new drugs, the American Society of Cancer and American Society of Clinical Oncology (ASCO), until now, do not endorse the prescription of other pharmacological therapy or nutraceutical besides duloxetine. The reason for that consensus is based on the absence of evidence for efficacy and safety for other therapies (Hershman et al., 2014; Hou et al., 2018). Table 1 reunites all clinical trials that investigated or plans to investigate pharmacological strategies to prevent or treat CINP. Several classes of drugs already known to be effective in the neuropathic pain control, such as antidepressants and anticonvulsants, have been pre-clinically and clinically tested and surprising the specialists with their absence of effect. We can cite gabapentin, pregabalin and amitriptyline (Table 1). This scenario leads to believe that it is a pathological condition with a profile significantly different from other neuropathies and, unfortunately, difficult to manage, since the great majority of the trials has failed to reduce the symptoms. New clinical trials are being conducted to evaluate new strategies focussing on the main mechanism of CINP, including oxidative stress, mitochondrial impairment and ion channels (more specifically TRP and $\mathrm{Na}^{+}$ channels) (Table 1).

Looking at the current scenario resumed in the Figure 3, there are 42 registered clinical trials investigating new pharmacological strategies to treat or prevent CINP. Most of them $(n=28)$ are conducted in the US. Only 27 studies have been completed and 4 have been terminated due to different reasons, including absence of participants and important side effects (Figure 4A). By the total, 9 studies support the therapy use against 12 that do not support it (Figure 4B). One third of the studies with successful results supports the use of duloxetine (Figure 4C). Observing this data, it is clear why the only therapy indicated by ASCO to treat CINP is duloxetine, all based on evidence of efficacy and safety.

\section{PEROXISOME PROLIFERATOR- ACTIVATED RECEPTORS}

Peroxisome proliferator-activated receptors (PPARs) are important members of the nuclear receptor family that cause the activation of several genes by acting as ligand-activated transcription factor (Berger and Moller, 2002). In mammals, there are three different PPAR isoforms: alpha $(\alpha)$, beta/delta $(\beta / \delta)$, and gamma $(\gamma)$, which are differentially expressed in several tissues (Heneka and Landreth, 2007). PPAR $\alpha$ (encoded by NR1C1) is ubiquitously expressed, but it is mostly found in tissues that present fatty acids high catabolic amounts, such as adipose tissue and liver, among others. It is also expressed in the lung, placenta, intestine, pancreas and skeletal muscle. Furthermore, PPAR $\beta / \delta$ (encoded by NR1C2) is also ubiquitously expressed and low levels are found in several tissues, such as muscle, adipose tissue and liver. PPAR $\gamma$ (encoded by NR1C3) has three different isoforms $(\gamma 1, \gamma 2$, and $\gamma 3)$ that display differences in tissue expression for each isoform: $\gamma 1$ has ubiquitous tissue expression, $\gamma 2$ is mostly expressed in adipose tissue, and $\gamma 3$ is expressed mainly in colon, macrophages and 


\section{NUMBER OF CINP PAPERS IN PUBMED}
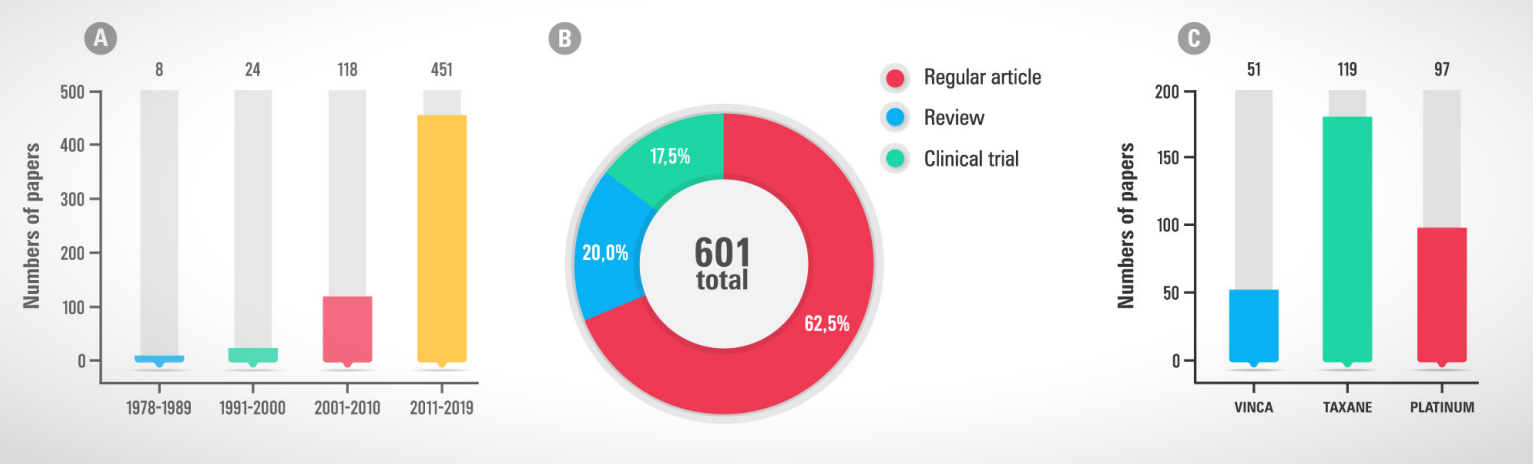

FIGURE 2 | (A) Number of scientific papers tagged "chemotherapy" and "peripheral neuropathy" and "pain" and "cancer" in Pubmed by decade of publication. (B) Types of publications, including regular article, review and clinical trial, found using the terms mentions in the first graph. (C) Number of papers mentioning the chemotherapy classes Vinca, Taxane and Platinum. Accessed in May 26 ${ }^{\text {th }}, 2019$.

adipose tissue (Han et al., 2017). Additionally, low levels of PPAR $\gamma$ were found in vascular smooth muscle, endothelium, hepatic stellate cells, bone marrow and neoplastic epithelial cells in breast, prostate, colon and bladder. This pattern of expression suggests that PPAR $\gamma$ may participate of many physiological and pathophysiological processes in different tissues (Guan and Breyer, 2001).

PPARs were originally identified in 1990 with the first cloning $(\mathrm{PPAR} \alpha)$ happening during molecular targeting for peroxisome proliferating agents in rodents (Issemann and Green, 1990). Since then, several fatty acids and by-products, including eicosanoids, have been identified as PPARs ligands and have also been shown to target many synthetic compounds currently used to treat diabetes and dyslipidaemias, such as thiazolidineodiones (TZDs), including pioglitazone and rosiglitazone, and fibrates (clofibrate) (Guan and Breyer, 2001; Seiri et al., 2019). Therefore, the knowledge of the molecular structure and physiological effects of these receptors becomes particularly important, both in the development and in the use of drugs to treat of metabolic diseases and others illness.

Independent of the PPAR type, all isoforms have similar structure (Korbecki et al., 2019). PPARs are composed of five different domains: A/B domain (amino-terminal region), domain $\mathrm{C}$ (DNA-DBD binding), domain $\mathrm{D}$ (hinge region), domain $\mathrm{E}$ (interaction with the linker - LDB) and domain $\mathrm{F}$ (Itoh et al., 2008; Figure 5). The amino-terminal (A/B) domain is extremely variable between the members of the nuclear receptor superfamily, both in size and amino acid sequence, and exhibits a transcriptional activation function that operates independently of the linker, termed activation function 1 (AF1) (Shao et al., 1998; Blanquart et al., 2003). The AF1 domain has an important role in the regulation of PPAR activity trough phosphorylation (Shao et al., 1998).

The domain $\mathrm{C}$ is the best-conserved part of the protein among the nuclear receptor family and its main function is the binding to DNA. This domain is in the central portion of the receptors and consists of two structural segments known as zinc fingers with nine cysteines. This domain controls gene expression through specific binding to the nucleotides sequences called the peroxisome proliferator responsive element (PPRE) after forming heterodimer with the retinoic $\mathrm{X}$ receptor (RXR) nuclear receptor (Guan and Breyer, 2001). There is a small region in the domain $\mathrm{D}$ that connects the $\mathrm{DBD}$ to the ligand-binding domain (LBD), or E domain, which is known as the hinge, allowing the rotation of the DBD in relation to the LBD (Guan and Breyer, 2001). The LDB domain is in the carboxy-terminal region and has several functions such as ligand recognition and homo and heterodimerisation of the receptor (Seiri et al., 2019). In addition to these functions, LBD contains a surface that is critical for transcriptional activation. After the activation of this region, called activation function 2 (AF-2), interaction with the co-activators occurs, which will allow the formation of the protein complex involved in the activation of the transcription (Guan and Breyer, 2001; Seiri et al., 2019).

Data from literature have shown that the transcription induced by PPARs is modulated by post-translational events, including phosphorylation, SUMOylation, ubiquitination and nitration (Van Beekum et al., 2009). However, the phosphorylation receives more attention by the researcher community for being the main determinant of PPAR $\gamma$ transcriptional activity, as already observed for oestrogen, progesterone and RXR receptors. However, its activity is determined by the intracellular localisation of the receptor, where nuclear migration leads to genomic effects, while cytosolic or cell membrane activation promotes DNA-independent effects (Cantini et al., 2010; Luconi et al., 2010). In fact, $\operatorname{PPAR} \gamma$ could regulate the different metabolic situations, such as lipid and glycidic homeostasis, inflammation and also cell proliferation by specifically modulating genes expression. The genomic mechanism is based on gene transcription regulation, where a PPAR ligand-bound receptor interacts with the RXR on specific PPRE in the promoter of specific target genes and recruits co-activator complexes that modify chromatin structure, enabling assembly of transcriptional machinery on 
TABLE 1 | Clinical trials for CIPN treatment using drugs or nutraceuticals around the world.

\begin{tabular}{|c|c|c|c|c|c|c|c|}
\hline Study & Trial \# & Country & Subjects & Start (yr) & Status & Remarks & References \\
\hline \multicolumn{8}{|l|}{ Antidepressant } \\
\hline \multirow[t]{4}{*}{ Duloxetin $\left(\right.$ Sinbalta $\left.{ }^{\circledR}\right)$} & UMIN000017647 & Japan & 70 & 2015 & Ongoing & Phase III & Matsuoka et al., 2017 \\
\hline & UMIN 000011554 & Japan & 34 & 2013 & Completed & $\begin{array}{l}\text { Phase II - pilot randomised trial; } \\
\text { reduction of pain symptoms }\end{array}$ & Hirayama et al., 2015 \\
\hline & NCT00489411 & United States & 231 & 2008 & Completed & $\begin{array}{l}\text { Phase III - significant reduction } \\
\text { of pain score }\end{array}$ & Smith et al., 2013 \\
\hline & NCT00489411 & United States & 106 & 2008 & Completed & $\begin{array}{l}\text { Phase III - significant reduction } \\
\text { of pain score }\end{array}$ & Smith et al., 2017 \\
\hline \multirow[t]{2}{*}{ Amitriptyline } & - & Finland & 114 & 2003 & Completed & $\begin{array}{l}\text { Preventive protocol; use not } \\
\text { supported }\end{array}$ & Kautio et al., 2008 \\
\hline & - & Finland & 44 & 2002 & Completed & $\begin{array}{l}\text { Therapeutic protocol; improve } \\
\text { symptoms of CINP }\end{array}$ & Kautio et al., 2008 \\
\hline \multicolumn{8}{|l|}{ Anticonvulsant } \\
\hline Gabapentin (Neurontin ${ }^{\circledR}$ ) & NCT00027963 & United States & 100 & 2002 & Completed & Phase III - use not supported & Rao et al., 2007 \\
\hline \multirow[t]{4}{*}{ Pregabalin (Lyrica $\left.{ }^{\circledast}\right)$} & NCT02394951 & United States & 26 & 2015 & Completed & Results not mentioned & \\
\hline & - & United States & 46 & 2012 & Completed & $\begin{array}{l}\text { Pilot study; PTX-treated } \\
\text { patients; use not supported }\end{array}$ & Shinde et al., 2016 \\
\hline & NCT00380874 & Europe/Asia $^{\mathrm{a}}$ & 61 & 2006 & Terminated & Phase IV & \\
\hline & NCT00407511 & Latin America ${ }^{\mathrm{b}}$ & 121 & 2006 & Completed & $\begin{array}{l}\text { Phase IV - not conclusive for } \\
\text { CINP }\end{array}$ & Xochilcal-Morales et al., 2010 \\
\hline Lamotrigine $\left(\right.$ Lamictal $\left.{ }^{\circledast}\right)$ & - & United States & 131 & 2004 & Completed & Use not supported & Rao et al., 2008 \\
\hline \multirow[t]{2}{*}{ Ethosuximide (Zarontin ${ }^{\circledR}$ ) } & NCT01278004 & United Kingdom & 15 & 2011 & Completed & Phase II - results not mentioned & \\
\hline & NCT02100046 & France & 114 & 2014 & Completed & Phase II - use not supported & Kerckhove et al., 2018 \\
\hline \multicolumn{8}{|l|}{ Antipsychotic } \\
\hline Loxapine & NCT02820519 & United States & 4 & 2016 & Terminated & $\begin{array}{l}\text { Phase II - intolerable high } \\
\text { amount of adverse effects }\end{array}$ & \\
\hline \multicolumn{8}{|l|}{ Associations } \\
\hline Memantine XR-pregabalin combination & NCT03272919 & United States & 20 & 2017 & Recruiting & Observational study & \\
\hline $\begin{array}{l}\text { Baclofen-Amitriptyline } \\
\text { Hydrochloride-Ketamine gel (BAK) }\end{array}$ & NCT00516503 & United States & 208 & 2007 & Completed & $\begin{array}{l}\text { Phase III - reduced pain } \\
\text { symptom }\end{array}$ & Barton et al., 2011 \\
\hline \multicolumn{8}{|l|}{ Opioid } \\
\hline Dextromethorphan (Robitussin ${ }^{\circledR}$ ) & NCT02271893 & France & 40 & 2014 & Recruiting & Phase II & Martin et al., 2015b \\
\hline \multicolumn{8}{|l|}{ Neuroprotector } \\
\hline Olesoxime (TRO19622) & NCT00876538 & France & 17 & 2009 & Completed & Phase II - results not mentioned & \\
\hline \multirow[t]{2}{*}{ Calmangafodipir (PledOx ${ }^{\circledR}$ ) } & NCT03654729 & United States & 420 & 2018 & Recruiting & Phase III & \\
\hline & NCT01619423 & United States & 186 & 2012 & Completed & $\begin{array}{l}\text { Phase I and II-OXA-treated } \\
\text { patients; reduced pain } \\
\text { symptom }\end{array}$ & Glimelius et al., 2018 \\
\hline
\end{tabular}


TABLE 1 | Continued

\begin{tabular}{|c|c|c|c|c|c|c|c|}
\hline Study & Trial \# & Country & Subjects & Start (yr) & Status & Remarks & References \\
\hline Leteprinim (Neotrofin $\left.{ }^{\circledR}\right)$ & NCT00041795 & United States & 50 & 2002 & Completed & Phase II - results not mentioned & \\
\hline Glutathione & & United States & 195 & 2009 & Completed & $\begin{array}{l}\text { Phase III - PTX-treated } \\
\text { patients; use not supported }\end{array}$ & Leal et al., 2014 \\
\hline \multicolumn{8}{|l|}{ Weight loss } \\
\hline Lorcaserin (Belviq ${ }^{\circledR}$ ) & NCT03812523 & United States & 50 & 2019 & Not yet recruiting & Phase II - OXA-treated patients & \\
\hline \multicolumn{8}{|l|}{ Cannabinoid agonists } \\
\hline Cannabinoids & NCT03782402 & United States & 100 & 2019 & Not yet recruiting & $\begin{array}{l}\text { Phase II - taxane-induced } \\
\text { neuropathy }\end{array}$ & \\
\hline Nabiximol (Sativex ${ }^{\circledR}$ ) & NCT00872144 & Canada & 16 & 2009 & Completed & $\begin{array}{l}\text { Phase III - reduced pain } \\
\text { symptoms }\end{array}$ & Lynch et al., 2014 \\
\hline Nabilone & NCT00380965 & United States & 23 & 2006 & Completed & $\begin{array}{l}\text { Phase IV - results not } \\
\text { mentioned }\end{array}$ & \\
\hline \multicolumn{8}{|l|}{ Toxins } \\
\hline Botulinum Toxin A & NCT03571334 & United States & 40 & 2018 & Not yet recruiting & Phase II & \\
\hline Tetrodotoxin & NCT01655823 & United States & 125 & 2012 & Terminated & $\begin{array}{l}\text { Phase II - interim analysis } \\
\text { determined the procedure to } \\
\text { phase III trial }\end{array}$ & \\
\hline \multicolumn{8}{|l|}{ Anaesthetic } \\
\hline Lidocaine & NCT03254394 & United States & 38 & 2017 & Recruiting & $\begin{array}{l}\text { Phase I/II - OXA-treated } \\
\text { patients }\end{array}$ & \\
\hline \multicolumn{8}{|l|}{ TRPs agonist } \\
\hline \multirow{2}{*}{$\begin{array}{l}\text { Capsaicin 8\% patch } \\
\left.\text { (Qutenza }{ }^{\circledR}\right)\end{array}$} & NCT03317613 & France & 84 & 2017 & Recruiting & Phase II & \\
\hline & - & Poland & 18 & 2013 & Completed & $\begin{array}{l}\text { OXA-treated patients; reduction } \\
\text { of pain symptoms }\end{array}$ & Filipczak-Bryniarska et al., 2017 \\
\hline Menthol & NCT01855607 & United States & 60 & 2013 & Unknown & Phase II & \\
\hline \multicolumn{8}{|l|}{ Nutraceutic } \\
\hline L-Carnitine L-tartrate & NCT00754767 & United States & 2 & 2007 & Terminated & $\begin{array}{l}\text { Phase IV - unable to accrue } \\
\text { study participants }\end{array}$ & \\
\hline \multirow[t]{3}{*}{ Acetyl L-carnitine } & NCT01526564 & China & 239 & 2012 & Completed & $\begin{array}{l}\text { Phase III - results not } \\
\text { mentioned }\end{array}$ & \\
\hline & NCT00775645 & United States & 437 & 2008 & Completed & Phase III - use not supported & Hershman et al., 2013 \\
\hline & NCT0058191 & United States & 32 & 2004 & Completed & Phase II - use not supported & Callander et al., 2014 \\
\hline Nicotinamide Riboside & NCT03642990 & United States & 39 & 2019 & Recruiting & Phase II & \\
\hline Omega-3/Nitamin D3 & NCT02294149 & Canada & 600 & 2014 & Unknown & Phase III & \\
\hline Vitamin E & NCT00363129 & United States & 207 & 2006 & Completed & Phase III - use not supported & Kottschade et al., 2011 \\
\hline$\alpha$-Lipoic acid & - & United States & 462 & & Completed & Use not supported & Guo et al., 2014 \\
\hline \multicolumn{8}{|l|}{ Antibiotic } \\
\hline Minocycline hydrochloride & NCT02297412 & United States & 47 & 2014 & Completed & $\begin{array}{l}\text { Phase II - PTX-treated patients; } \\
\text { use not supported }\end{array}$ & Pachman et al., 2017 \\
\hline
\end{tabular}




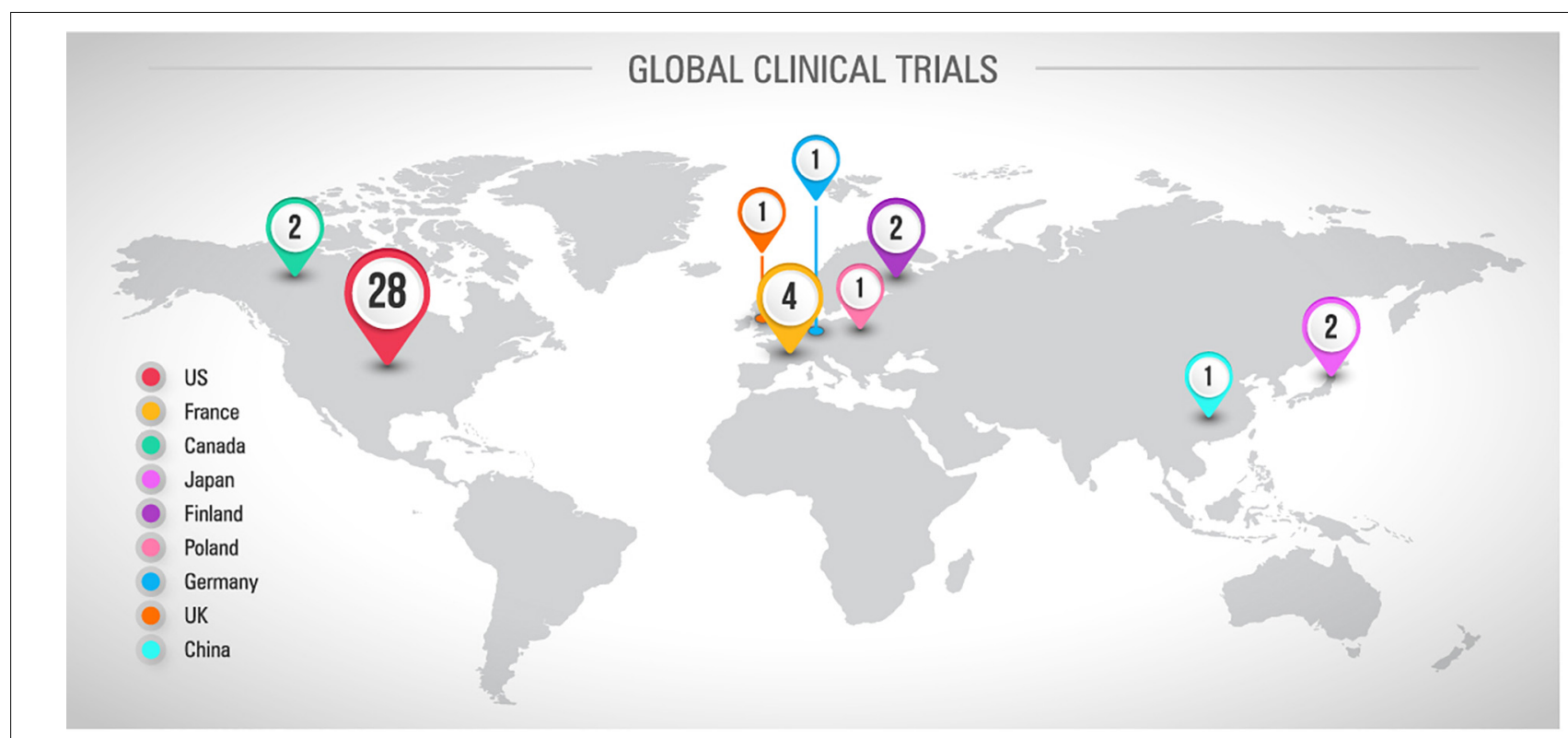

FIGURE 3 | Global distribution of registered and published clinical trials involving CINP and drugs or nutraceuticals. Sources: Pubmed and www. ClinicalTrials.gov, accessed in April $26^{\text {th }}, 2019$.

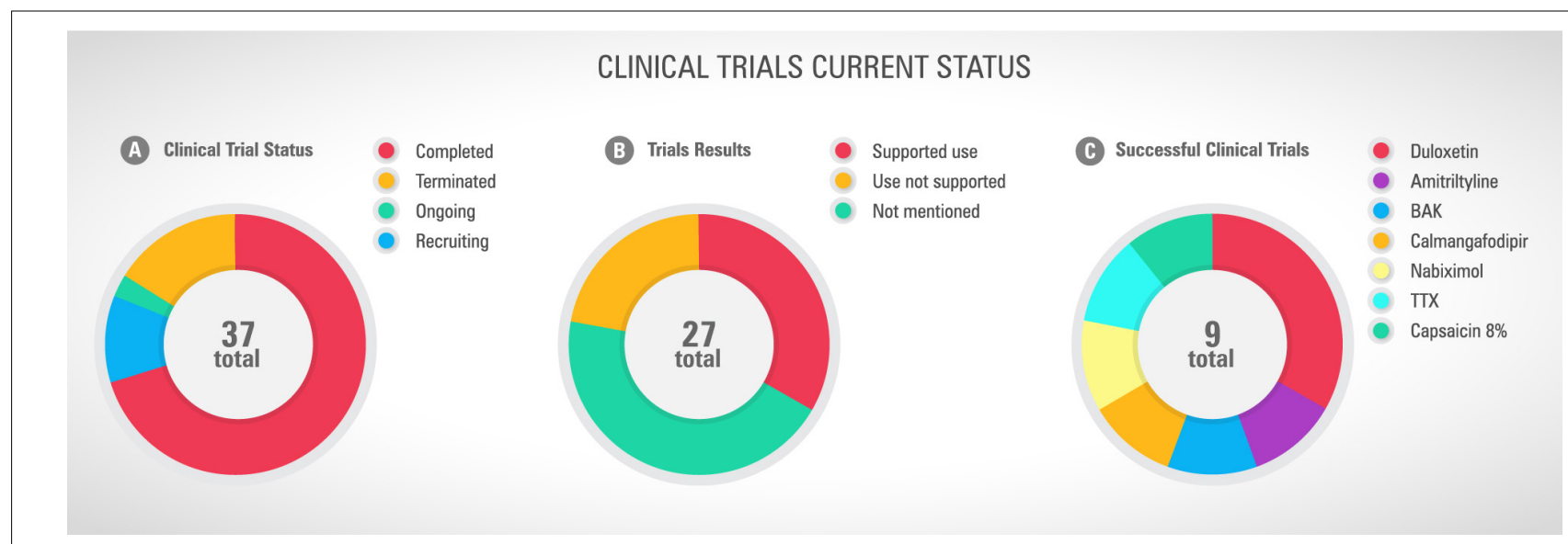

FIGURE 4 | (A) Current clinical trial status, (B) studies successfully completed and their results, and (C) drugs or nutraceuticals with recommended use. Sources: Pubmed and www. ClinicalTrials.gov, accessed in April $26^{\text {th }}, 2019$.

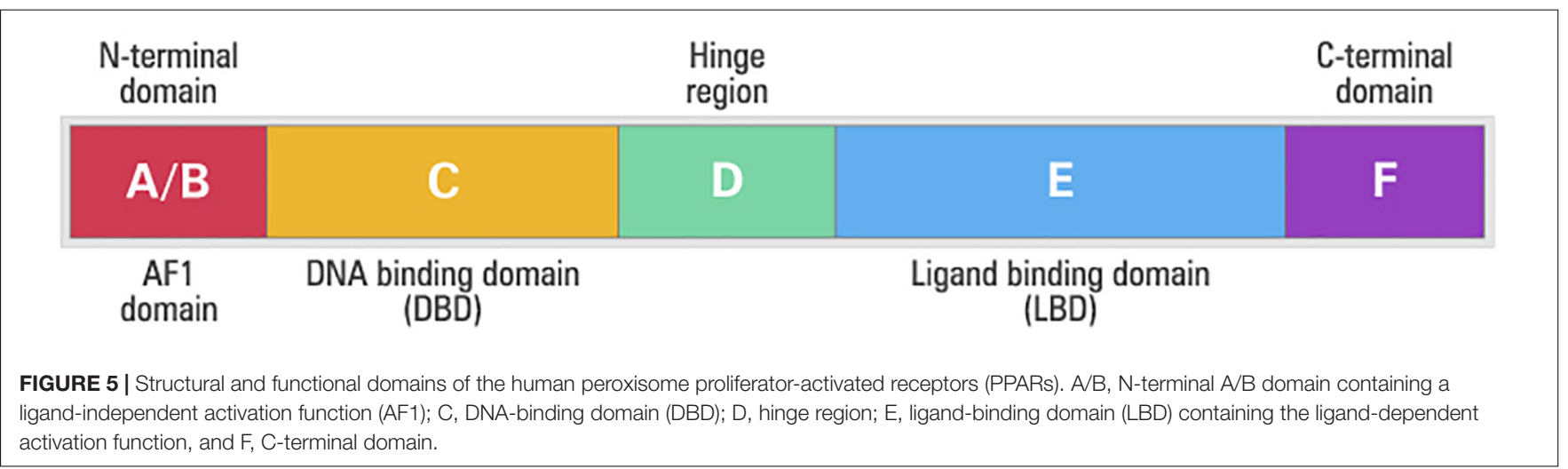


the promoter (Korbecki et al., 2019). However, some effects of PPARs are correlated with trans-repression mechanism, mainly the anti-inflammatory effects, blocking the transcription factors activity, such as NF-kB and AP-1 (Daynes and Jones, 2002; Pawlak et al., 2012). Known as non-genomic pathway, this effect of PPARs has been in the spotlight, where the mechanism did not involve enhancement or inhibition of gene transcription. The non-genomic effects are correlated to the fast modulation of intracellular activity, including kinases and phosphatases. Therefore, the mechanism that mediates rapid action is still controversial (Brown, 1981).

Independent of the mechanism, it is important to emphasise that PPAR, mainly PPAR $\gamma$, is highly expressed in different types of cells. In the CNS, PPAR $\gamma$ have been described to be expressed in the cortex and spinal cord, and also in the microglia and astrocytes (Kainu et al., 1994; Cullingford et al., 1998; Cristiano et al., 2001; Benani et al., 2003; Bernardo et al., 2003; Moreno et al., 2004; for review see, Okine et al., 2019). However, PPAR $\gamma$ is more expressed in neurons than in astrocytes or microglia (Warden et al., 2016).

The PPAR $\gamma$ is the most well-studied member of the PPAR family of nuclear receptors, and both ligand-dependent and ligand-independent modes of modulation of its activity have been established. In this context, PPAR $\gamma$ modulation has been currently focussed in the market and in the scientific research of new drug discovery. The research is based mainly in metabolic and neurodegenerative disorders, and other conditions where CNS is affected as neuropathic pain (Okine et al., 2019).

\section{PPAR $\gamma$ AGONISTS TO TREAT CINP}

Thiazolidineodiones, or simply "glitazones," belong to a class of compounds that activates PPAR $\gamma$ and can be employed to treat type 2 diabetes and metabolic syndrome (Sauer, 2015). Ciglitazone was the first drug described as an insulin sensitiser, and TZDs were recognised as PPAR $\gamma$ agonists in 1995. Two years later, the FDA approved the clinical use of troglitazone. In 1999, two new drugs, rosiglitazone and pioglitazone, entered in the hall of anti-diabetic drugs. Unfortunately, what seemed to be a future of success, ended with the troglitazone removed from the market in 2000 because of significant liver toxicity. On the other hand, pioglitazone and rosiglitazone remain in clinical practice, despite their association with increased bladder cancer risk and cardiovascular disease, respectively (Sauer, 2015).

In addition to the treatment of diabetes, PPAR $\gamma$ agonists have been considered potential therapeutic drugs to treat a large amount of neurological conditions, such as neurodegenerative diseases, traumatic injury, demyelinating diseases and chronic pain (Jin et al., 2013; Swanson et al., 2013; Vallee and Lecarpentier, 2016; Patel et al., 2017; Villapol, 2018). Recently, it was published a comprehensive review compiling all studies of PPAR agonists in different types of pain models (Okine et al., 2019). Pioglitazone, rosiglitazone and $15 \mathrm{~d}-\mathrm{PGJ}_{2}$ have been largely employed in pre-clinical studies using different models of neuropathic pain in rodents, showing anti-nociceptive effect by reducing oxidative stress and inflammation in the DRG and spinal cord (Table 2; Okine et al., 2019).

The expression of PPAR $\gamma$ at both mRNA and protein levels was found in the spinal cord of rats, and the intrathecal injection of PPAR $\gamma$ agonists (15d-PGJ 2 or rosiglitazone) was able to reverse mechanical allodynia induced by spare nerve injury (SNI) in rats, indicating that PPAR $\gamma$ is functionally expressed in the spinal cord (Churi et al., 2008). The immunoreactivity for PPAR $\gamma$ was also found in the mouse DRG and spinal cord neurons, as well as in sciatic nerve adipocytes, where the receptor was believed to mediate the anti-allodynic effect of pioglitazone by controlling inflammation (Maeda et al., 2008). Despite no data about the spinal levels of PPAR $\gamma$ in injured animals, a further study showed that PPAR $\gamma$ activity was not altered by SNI in rats, but it was significantly increased by the treatment of animals with R-flurbiprofen; the increase in PPAR $\gamma$ activity was proposed to be one of the mechanisms involved in the antinociceptive effect of R-flurbiprofen in the SNI model (Bishay et al., 2010). $\operatorname{PPAR} \gamma$ was also suggested to meditate the antinociceptive effect of palmitoylethanolamide on the chronic constriction injury (CCI) model of neuropathic pain (Costa et al., 2008).

As previously mentioned, mitochondrial dysfunction, oxidative stress and, consequently, neuronal injury in the DRG and spinal cord are key events in the physiopathology of CINP. Therefore, TZDs could have beneficial effects on CINP by limiting some, if not all, of these events. In fact, several studies have proposed that the main mechanisms of action of $\operatorname{PPAR} \gamma$ agonists are the protection of mitochondrial function and antioxidant activity, including the upregulation of mitochondrial oxidative phosphorylation and biogenesis, and improvement of endogenous oxidant defences (for review see, Corona and Duchen, 2016). Indeed, TZDs were able to protect cortical astrocytes and neuroblastoma derived cell line by promoting mitochondrial biogenesis (Dello Russo et al., 2003; Miglio et al., 2009). Also, ciglitazone reduced the oxidative stress in hippocampal neurons and, consequently, prevented the mitochondrial damage (Zolezzi et al., 2013). The protective effects of TZDs were also attributed to their ability of reducing apoptosis associated with oxidative stress (Hunter et al., 2007; Wang et al., 2011). In a rat model of spinal nerve ligation (SNL), pioglitazone alone or in association with ceftriaxone was able to ameliorate neuropathic pain by restoring the activity of mitochondrial enzyme complex activities, increasing the levels of reduced glutathione (GSH), superoxide dismutase (SOD) and catalase, and reducing oxidative damage in the rat spinal cord (Pottabathini et al., 2016). The treatment of rodents with oxaliplatin or cisplatin caused an imbalance between the oxidative stress and the level of antioxidant enzymes in the DRG and spinal cord of treated animals (Zanardelli et al., 2014; Khasabova et al., 2019). In these studies, rosiglitazone was effective in preventing oxaliplatin-induced mechanical and cold hyperalgesia by inhibiting oxidative stress and increasing catalase activity in the DRG and spinal cord of rats (Zanardelli et al., 2014). Additionally, in a recent publication Khasabova et al. (2019) demonstrated that pioglitazone reduced cisplatin-induced neuropathic pain in mice, suggesting the improvement of antioxidant enzymes activity and protection against oxidative 
TABLE 2 | Pre-clinical studies investigating PPARy agonists effects in experimental neuropathic pain models.

\begin{tabular}{|c|c|c|c|c|c|}
\hline Glitazones & Model & Specie & Main effects & Mechanism of action & References \\
\hline $\begin{array}{l}\text { Pioglitazone and } \\
\text { Rosiglitazone }\end{array}$ & Spinal cord injury & Rats & $\begin{array}{l}\text { Improvement of motor function recovery and } \\
\text { prevention of heat hypersensitivity. }\end{array}$ & $\begin{array}{l}\text { Reduction of neuronal damage, inflammation } \\
\text { and myelin loss in the spinal cord. }\end{array}$ & Park et al., 2007 \\
\hline Pioglitazone & Partial sciatic nerve ligation & Mice & $\begin{array}{l}\text { Reversal of mechanical allodynia and heat } \\
\text { hyperalgesia. }\end{array}$ & $\begin{array}{l}\text { Reduction of inflammation in the sciatic nerve, } \\
\text { DRG and spinal cord. }\end{array}$ & Maeda et al., 2008 \\
\hline Rosiglitazone & Spared Nerve Injury & Rats & Reversal of mechanical and cold allodynia. & $\begin{array}{l}\text { Transcription-independent mechanism in the } \\
\text { spinal cord. }\end{array}$ & Churi et al., 2008 \\
\hline Rosiglitazone & Tibial and sural nerve transection & Rats & $\begin{array}{l}\text { Attenuation of mechanical and cold } \\
\text { hyperalgesia. }\end{array}$ & $\begin{array}{l}\text { Inhibition of oxidative stress and inflammation in } \\
\text { the sciatic nerve. }\end{array}$ & Jain et al., 2009 \\
\hline Rosiglitazone & Partial sciatic nerve ligation & Mice & Attenuation of mechanical allodynia & $\begin{array}{l}\text { Regulation of macrophage infiltration and } \\
\text { pro-inflammatory molecules production in the } \\
\text { sciatic nerve. }\end{array}$ & Takahashi et al., 2011 \\
\hline Pioglitazone & Spared nerve injury & Rats & $\begin{array}{l}\text { Prevention of mechanical and cold } \\
\text { hypersensitivities }\end{array}$ & $\begin{array}{l}\text { Inhibition of microglia and/or astrocyte } \\
\text { activation in the spinal cord. }\end{array}$ & Morgenweck et al., 2013 \\
\hline Pioglitazone & Spinal nerve transection & Rats & Prevention of mechanical hypersensitivity & Inhibition of neuro-inflammation in spinal cord. & Jia et al., 2013 \\
\hline Rosiglitazone & Oxaliplatin-induced neuropathic pain & Rats & Prevention of mechanical and cold hyperalgesia & $\begin{array}{l}\text { Prevention of oxidative stress in the DRG and } \\
\text { spinal cord by increasing catalase activity. }\end{array}$ & Zanardelli et al., 2014 \\
\hline Pioglitazone & Spared Nerve Injury & Rats & Reversal of mechanical and cold allodynia & $\begin{array}{l}\text { Inhibition of astrocyte activation by } \\
\text { non-genomic mechanisms. }\end{array}$ & Griggs et al., 2015 \\
\hline Pioglitazone & Spinal nerve ligation & Rats & $\begin{array}{l}\text { Prevention of mechanical, cold and heat } \\
\text { hypersensitivities }\end{array}$ & $\begin{array}{l}\text { Inhibition of oxidative stress, inflammation and } \\
\text { apoptosis in the spinal cord. }\end{array}$ & Pottabathini et al., 2016 \\
\hline Pioglitazone & Trigeminal inflammatory compression & Mice & Attenuation of mechanical allodynia & $\begin{array}{l}\text { Activation of PPAR } \gamma \text { in the trigeminal brainstem } \\
\text { sensory nucleus. }\end{array}$ & Lyons et al., 2017 \\
\hline Pioglitazone & Cisplatin-induced neuropathic pain & Mice & Reduction of mechanical and cold hyperalgesia & $\begin{array}{l}\text { Reduction of oxidative stress in the DRG by } \\
\text { increasing SOD activity. }\end{array}$ & Khasabova et al., 2019 \\
\hline
\end{tabular}


stress as the main mechanisms. Besides, pioglitazone was able to increase the sensitivity of cancer cells to the chemotherapy, reducing the levels of its concentration to block cell proliferation (Khasabova et al., 2019). Taken together, these studies suggest that PPAR $\gamma$ agonists could prevent CINP and improve the efficacy of cancer chemotherapy.

Neuroinflammation in the spinal cord is an important imprint of neuropathic pain that contributes to the chronicity of pain. Studies using the mouse model of paclitaxel-induced neuropathic pain have shown increased immunostaining for Iba-1 (microglia marker) and augmented levels of NF- $\kappa$ B, cytokines and chemokines in the spinal cord of paclitaxel-treated mice (Segat et al., 2017; Manjavachi et al., 2019). Also, the release of kinins and the activation of their receptors $\left(B_{1}\right.$ and $B_{2}$ receptors) in the spinal cord seem to be important for paclitaxel-induced neuropathic pain in mice (Costa et al., 2011). The blockage of spinal cord neuroinflammation using natural compounds, monoclonal antibodies or antagonists (for kinin $\mathrm{B} 1, \mathrm{~B} 2$ or CXCR2 receptors) has been shown to prevent and revert pain-like behaviours in paclitaxel-treated mice (Costa et al., 2011, 2018; Segat et al., 2017; Manjavachi et al., 2019). Therefore, PPAR $\gamma$ agonists could be effective pharmacological tools to treat CINP by reducing the inflammatory process in the spinal cord or even in the DRG. In fact, the non-genomic activity of PPAR $\gamma$ has been extensively co-related with its anti-inflammatory property, characterising TZDs as important blockers of protein transcription (Sauer, 2015). Additionally, several studies have demonstrated an important link between the efficacy of PPAR $\gamma$ agonists on neuropathic pain and the suppression of inflammatory gene expression (including cytokines and cytokines) (Maeda and Kishioka, 2009; Freitag and Miller, 2014).

While DRGs and spinal cord are considered the most likely structures involved in the anti-nociceptive effect of TZDs, the cell types mediating their actions are not well-characterised. However, the expression of PPAR $\gamma$ in both neuronal and non-neuronal cells has been shown (Lu et al., 2011). PPAR $\gamma$ expressed in astrocytes was proposed to regulate oxidative stress, as the impairment in its activity reduced catalase activity, a key antioxidant defence enzyme (Di Cesare Mannelli et al., 2014). In the CNS, PPAR $\gamma$ activation reduced JNK and NF-KB signalling, as well as JAK/STAT pathway, modulating the activity of adaptive immune cells, myeloid cells and astrocytes (Daynes and Jones, 2002; Bright et al., 2008). PPAR $\gamma$ activation is also able to reduce the levels of inflammatory and neurotoxic mediators produced by macrophages and astrocytes and stimulate the infiltration of regulatory T cells (Ferret-Sena et al., 2018).

\section{POTENTIAL EFFECT OF PPAR $\gamma$ AGONISTS ON CANCER}

In 2008, PPAR Research Journal published several reviews regarding the role of PPAR and its agonists in cancer and the possible mechanisms involving on it. Taking the last decade, approximately 1,400 regular articles and clinical trials have been published evaluating the involvement of PPAR $\gamma$ on cancer development and its modulation or even anti-cancer profile of
PPAR $\gamma$ agonists (data extracted from PUBMED on $24^{\text {th }}$ July using the terms "PPAR $\gamma$ and cancer"). Considering the current year (2019), 14 studies revels the strong potential of PPAR $\gamma$ as target to promote reduction in neoplastic cell proliferation and migration. It demonstrates that this receptor and its signalling pathways are in the pipeline of new drugs for the treatment of patients with different types of cancer.

As previously described, pioglitazone was linked to a high risk of developing bladder cancer, which was seriously considered by the medical community in case of PPAR $\gamma$ prescription to patients with cancer or familiar history. Recently, Rochel et al. (2019) have shown that mutations in the PPAR $\gamma$ protein are responsible for the pro-oncogenic activity of the heterodimer PPAR $\gamma / R X R \alpha$, leading to bladder luminal cancer. This discovery reintroduces the receptor among the promisor new targets to treat cancer, and considering that co-morbidities, such as metabolic syndrome, have strong implication in cancer development, it becomes more significant.

Besides that, PPAR $\gamma$ gain more pros than cons with the studies that demonstrate the activity of their ligands as cancer suppressors. Here we are going to mention the important results obtained with PPAR $\gamma$ activation published only this year. Piccinin et al. (2019) demonstrated that the administration of PGC1, a PPAR $\gamma$ activator, was able to reduce the progression of hepatocellular carcinoma. The enhanced invasion and migration of colorectal cancer cells promoted by the microRNA-11 was reverted by the increase of PPAR $\gamma$ expression induced by Fatty Acid Binding Protein 4 (FABP4) activation (Zhao et al., 2019). In fact, it was previously shown that the inhibition of the oncogenic Src culminated in the enhancement of the axis FABP4/PPAR $\gamma$, working as tumour repressor (Hua et al., 2019).

TZD18, a dual PPAR $\gamma / \alpha$ ligand, reduced the growth and increased the apoptosis of human gastric cancer cells by increasing the expression of BAX and p27kip1 and decreasing Bcl-2 (Ma et al., 2019). Similar activity was observed for renal carcinoma cells (Wu et al., 2019), cutaneous squamous cell carcinoma cells (Wolff et al., 2019), non-small cell lung carcinoma (Liu and Fang, 1983; Ciaramella et al., 2019) and prostate cancer cells (Masure et al., 1983). Ciaramella et al. (2019) also correlated the anti-cancer activity of PPAR $\gamma$ to its effects on cancer microenvironment bioenergetics and metabolism.

Furthermore, the PPAR $\gamma$ was also implicated in the enhancement of doxorubicin cytotoxic effect of K562 resistant cells after treatment with ciglitazone, emphasising its important role in the multidrug resistance (MDR) activity. Additionally, Lv et al. (2019) demonstrated that PPAR $\gamma$ expression in cancer cells is related to favourable prognostic of patients with bladder cancer and that the in vitro and in vivo administration of pioglitazone or rosiglitazone was responsible for enhancing the cell cycle G2 arrest and apoptosis, followed by reduction in cell proliferation and tumour growth through PI3K-AKT pathway.

\section{CONCLUDING REMARKS}

Safe and effective therapies to prevent or treat CINP are still an unmet clinical need. Drugs normally effective against chronic pain conditions, such as gabapentin and tricyclic 
antidepressants, failed to relieve CINP. The physiopathology of CINP involves a complex machinery where mitochondrial impairment and oxidative stress are key elements, leading to cell death, neuronal damage and inflammatory process. PPAR $\gamma$ agonists can protect cells against mitochondrial damage and the deleterious effect of oxidative stress, and interfere with the synthesis of important chemical mediators, such as cytokines and chemokines. Therefore, the use of PPAR $\gamma$ agonists to treat CINP have provoked the interest of scientists and clinicians. In fact, rosiglitazone and pioglitazone have shown antinociceptive effect on chronic pain models, including neuropathic pain induced by platinum-based drugs, by increasing the antioxidant defences and reducing oxidative stress. Additionally, PPAR $\gamma$ agonists have been pointed as potential pharmacological tools to suppress cancer progression. Therefore, the use of TZDs in the treatment of CINP could also have a positive impact on cancer treatment, what is favourable to the use of these drugs in cancer patients.

Despite being a promising pharmacological strategy, further studies are essential to support the use of TZDs in treatment of CINP. First, the effect of TZDs on neuropathic pain induced by other anticancer agents, such as paclitaxel or bortezomib, should also be addressed. Second, the mechanisms of action of these drugs on CINP must be fully characterised (for example, the effect of TZDs on neuroinflammation associated with CINP has not yet been evaluated). Finally, joint effort of chemists, pharmacologists and physicians should prioritise the search for new PPAR $\gamma$ agonists, with reduced side effects,

\section{REFERENCES}

Abalo, R., Uranga, J. A., Perez-Garcia, I., De Andres, R., Giron, R., Vera, G., et al. (2017). May cannabinoids prevent the development of chemotherapyinduced diarrhea and intestinal mucositis? experimental study in the rat. Neurogastroenterol. Motil. 29, 1-14. doi: 10.1111/nmo.12952

Abram, S. E., Yi, J., Fuchs, A., and Hogan, Q. H. (2006). Permeability of injured and intact peripheral nerves and dorsal root ganglia. Anesthesiology 105, 146-153. doi: 10.1097/00000542-200607000-00024

Andrews, P. L., and Sanger, G. J. (2014). Nausea and the quest for the perfect anti-emetic. Eur. J. Pharmacol. 722, 108-121. doi: 10.1016/j.ejphar.2013.09.072

Areti, A., Yerra, V. G., Naidu, V., and Kumar, A. (2014). Oxidative stress and nerve damage: role in chemotherapy induced peripheral neuropathy. Redox Biol. 2, 289-295. doi: 10.1016/j.redox.2014.01.006

Argyriou, A. A., Kyritsis, A. P., Makatsoris, T., and Kalofonos, H. P. (2014). Chemotherapy-induced peripheral neuropathy in adults: a comprehensive update of the literature. Cancer Manag. Res. 6, 135-147. doi: 10.2147/CMAR. S44261

Barton, D. L., Wos, E. J., Qin, R., Mattar, B. I., Green, N. B., Lanier, K. S., et al. (2011). A double-blind, placebo-controlled trial of a topical treatment for chemotherapy-induced peripheral neuropathy: NCCTG trial N06CA. Support. Care Cancer 19, 833-841. doi: 10.1007/s00520-010-0911-0

Benani, A., Kremarik-Bouillaud, P., Bianchi, A., Netter, P., Minn, A., and Dauca, M. (2003). Evidence for the presence of both peroxisome proliferator-activated receptors alpha and beta in the rat spinal cord. J. Chem. Neuroanat. 25, 29-38. doi: 10.1016/s0891-0618(02)00093-5

Bennett, G. J., Timothy, D., and Daniela, S. (2014). Mitotoxicity in distal symmetrical sensory peripheral neuropathies. Nat. Rev. Neurol. 10, 326-336. doi: $10.1038 /$ nrneurol.2014.77

Berger, J., and Moller, D. E. (2002). The mechanisms of action of PPARs. Annu. Rev. Med. 53, 409-435. doi: 10.1146/annurev.med.53.082901.104018

Bernardo, A., Ajmone-Cat, M. A., Levi, G., and Minghetti, L. (2003). 15-deoxydelta12,14-prostaglandin $\mathrm{J} 2$ regulates the functional state and the survival of good permeability at blood brain barrier and positive effects in reducing CINP.

\section{AUTHOR CONTRIBUTIONS}

All authors listed have made a substantial, direct and intellectual contribution to the work, and approved it for publication.

\section{FUNDING}

This work was supported by grants from the Conselho Nacional de Desenvolvimento Científico e Tecnológico (CNPq) and the Fundação de Apoio a Pesquisa Científica e Tecnológica do Estado de Santa Catarina (FAPESC). LS is a Ph.D. student, recipient of CAPES grant (Financial code 001). TC and JM are graduate students, recipients of CNPq (PIBIC) grant (Financial code 001). JS and NQ were granted by CNPq (Financial code 001). RC was a Newton International Fellow at the King's College London granted by The Royal Society and CAPES (Financial code 001).

\section{ACKNOWLEDGMENTS}

We are grateful to C. Scheidt for his help in the conception of the Figures 1-5 illustrations.

microglial cells through multiple molecular mechanisms. J. Neurochem. 87, 742-751. doi: 10.1046/j.1471-4159.2003.02045.x

Binder, A., and Baron, R. (2016). The pharmacological therapy of chronic neuropathic pain. Dtsch. Arztebl. Int. 113, 616-625. doi: 10.3238/arztebl.2016. 0616

Bishay, P., Schmidt, H., Marian, C., Haussler, A., Wijnvoord, N., Ziebell, S., et al. (2010). R-flurbiprofen reduces neuropathic pain in rodents by restoring endogenous cannabinoids. PLoS One 5:e10628. doi: 10.1371/journal.pone. 0010628

Blanquart, C., Barbier, O., Fruchart, J. C., Staels, B., and Glineur, C. (2003). Peroxisome proliferator-activated receptors: regulation of transcriptional activities and roles in inflammation. J. Steroid Biochem. Mol. Biol. 85, 267-273. doi: 10.1016/s0960-0760(03)00214-0

Bonadonna, G., Brusamolino, E., Valagussa, P., Rossi, A., Brugnatelli, L., Brambilla, C., et al. (1976). Combination chemotherapy as an adjuvant treatment in operable breast cancer. N. Engl. J. Med. 294, 405-410.

Borcoman, E., and Le Tourneau, C. (2016). Antibody drug conjugates: the future of chemotherapy? Curr. Opin. Oncol. 28, 429-436. doi: 10.1097/cco. 0000000000000310

Bray, F., Ferlay, J., Soerjomataram, I., Siegel, R. L., Torre, L. A., and Jemal, A. (2018). Global cancer statistics 2018: GLOBOCAN estimates of incidence and mortality worldwide for 36 cancers in 185 countries. CA Cancer J. Clin. 68, 394-424. doi: 10.3322/caac.21492

Bright, J. J., Kanakasabai, S., Chearwae, W., and Chakraborty, S. (2008). PPAR regulation of inflammatory signaling in CNS diseases. PPAR Res. 2008:658520. doi: $10.1155 / 2008 / 658520$

Brown, I. D. (1981). Some further observations on submerging deciduous molars. Br. J. Orthod. 8, 99-107. doi: 10.1179/bjo.8.2.99

Brown, T. J., Sedhom, R., and Gupta, A. (2019). Chemotherapy-induced peripheral neuropathy. JAMA Oncol. 5:750.

Callander, N., Markovina, S., Eickhoff, J., Hutson, P., Campbell, T., Hematti, P., et al. (2014). Acetyl-L-carnitine (ALCAR) for the prevention of chemotherapyinduced peripheral neuropathy in patients with relapsed or refractory multiple 
myeloma treated with bortezomib, doxorubicin and low-dose dexamethasone: a study from the wisconsin oncology network. Cancer Chemother. Pharmacol. 74, 875-882. doi: 10.1007/s00280-014-2550-5

Cantini, G., Lombardi, A., Borgogni, E., Francalanci, M., Ceni, E., Degl'innocenti, S., et al. (2010). Peroxisome-proliferator-activated receptor gamma (PPARgamma) is required for modulating endothelial inflammatory response through a nongenomic mechanism. Eur. J. Cell Biol. 89, 645-653. doi: 10.1016/j.ejcb.2010.04.002

Carozzi, V. A., Canta, A., and Chiorazzi, A. (2015). Chemotherapy-induced peripheral neuropathy: what do we know about mechanisms? Neurosci. Lett. 596, 90-107. doi: 10.1016/j.neulet.2014.10.014

Carvalho, L. F., Silva, A. M. F., and Carvalho, A. A. (2017). The use of antioxidant agents for chemotherapy-induced peripheral neuropathy treatment in animal models. Clin. Exp. Pharmacol. Physiol. 44, 971-979. doi: 10.1111/1440-1681. 12803

Chabner, B. A., and Roberts, T. G. Jr. (2005). Timeline: chemotherapy and the war on cancer. Nat. Rev. Cancer 5, 65-72. doi: 10.1038/nrc1529

Churi, S. B., Abdel-Aleem, O. S., Tumber, K. K., Scuderi-Porter, H., and Taylor, B. K. (2008). Intrathecal rosiglitazone acts at peroxisome proliferator-activated receptor-gamma to rapidly inhibit neuropathic pain in rats. J. Pain 9, 639-649. doi: 10.1016/j.jpain.2008.02.002

Ciaramella, V., Sasso, F. C., Di Liello, R., Corte, C. M. D., Barra, G., Viscardi, G., et al. (2019). Activity and molecular targets of pioglitazone via blockade of proliferation, invasiveness and bioenergetics in human NSCLC. J. Exp. Clin. Cancer Res. 38:178. doi: 10.1186/s13046-019-1176-1

Colvin, L. A. (2019). Chemotherapy-induced peripheral neuropathy: where are we now? Pain 160(Suppl. 1), S1-S10. doi: 10.1097/j.pain.0000000000001540

Corona, J. C., and Duchen, M. R. (2016). PPARgamma as a therapeutic target to rescue mitochondrial function in neurological disease. Free Radic. Biol. Med. 100, 153-163. doi: 10.1016/j.freeradbiomed.2016.06.023

Costa, B., Comelli, F., Bettoni, I., Colleoni, M., and Giagnoni, G. (2008). The endogenous fatty acid amide, palmitoylethanolamide, has anti-allodynic and anti-hyperalgesic effects in a murine model of neuropathic pain: involvement of CB(1), TRPV1 and PPARgamma receptors and neurotrophic factors. Pain 139, 541-550. doi: 10.1016/j.pain.2008.06.003

Costa, R., Bicca, M. A., Manjavachi, M. N., Segat, G. C., Dias, F. C., Fernandes, E. S., et al. (2018). Kinin receptors sensitize TRPV4 channel and induce mechanical hyperalgesia: relevance to paclitaxel-induced peripheral neuropathy in mice. Mol. Neurobiol. 55, 2150-2161. doi: 10.1007/s12035-017-0475-9

Costa, R., Motta, E. M., Dutra, R. C., Manjavachi, M. N., Bento, A. F., Malinsky, F. R., et al. (2011). Anti-nociceptive effect of kinin $\mathrm{B}(1)$ and $\mathrm{B}(2)$ receptor antagonists on peripheral neuropathy induced by paclitaxel in mice. $\mathrm{Br} . J$. Pharmacol. 164, 681-693. doi: 10.1111/j.1476-5381.2011.01408.x

Cristiano, L., Bernardo, A., and Ceru, M. P. (2001). Peroxisome proliferatoractivated receptors (PPARs) and peroxisomes in rat cortical and cerebellar astrocytes. J. Neurocytol. 30, 671-683.

Cullingford, T. E., Bhakoo, K., Peuchen, S., Dolphin, C. T., Patel, R., and Clark, J. B. (1998). Distribution of mRNAs encoding the peroxisome proliferatoractivated receptor alpha, beta, and gamma and the retinoid $\mathrm{X}$ receptor alpha, beta, and gamma in rat central nervous system. J. Neurochem. 70, 1366-1375. doi: 10.1046/j.1471-4159.1998.70041366.x

Daynes, R. A., and Jones, D. C. (2002). Emerging roles of PPARs in inflammation and immunity. Nat. Rev. Immunol. 2, 748-759. doi: 10.1038/nri912

Dello Russo, C., Gavrilyuk, V., Weinberg, G., Almeida, A., Bolanos, J. P., Palmer, J., et al. (2003). Peroxisome proliferator-activated receptor gamma thiazolidinedione agonists increase glucose metabolism in astrocytes. J. Biol. Chem. 278, 5828-5836. doi: 10.1074/jbc.m208132200

Devita, V. T. Jr., and Chu, E. (2008). A history of cancer chemotherapy. Cancer Res. 68, 8643-8653. doi: 10.1158/0008-5472.CAN-07-6611

Di Cesare Mannelli, L., Zanardelli, M., Micheli, L., and Ghelardini, C. (2014). PPAR- gamma impairment alters peroxisome functionality in primary astrocyte cell cultures. Biomed. Res. Int. 2014:546453. doi: 10.1155/2014/ 546453

Doroshow, J. H., and Kummar, S. (2014). Translational research in oncology10 years of progress and future prospects. Nat. Rev. Clin. Oncol. 11, 649-662. doi: 10.1038/nrclinonc.2014.158

Duggett, N. A., Griffiths, L. A., and Flatters, S. J. L. (2017). Paclitaxel-induced painful neuropathy is associated with changes in mitochondrial bioenergetics, glycolysis, and an energy deficit in dorsal root ganglia neurons. Pain 158, 1499-1508. doi: 10.1097/j.pain.0000000000000939

Duggett, N. A., Griffiths, L. A., Mckenna, O. E., De Santis, V., Yongsanguanchai, N., Mokori, E. B., et al. (2016). Oxidative stress in the development, maintenance and resolution of paclitaxel-induced painful neuropathy. Neuroscience 333, 13-26. doi: 10.1016/j.neuroscience.2016.06.050

Ferlay, J., Colombet, M., Soerjomataram, I., Mathers, C., Parkin, D. M., Pineros, M., et al. (2019). Estimating the global cancer incidence and mortality in 2018: GLOBOCAN sources and methods. Int. J. Cancer 144, 1941-1953. doi: 10.1002/ ijc.31937

Ferlay, J., Soerjomataram, I., Dikshit, R., Eser, S., Mathers, C., Rebelo, M., et al. (2015). Cancer incidence and mortality worldwide: sources, methods and major patterns in GLOBOCAN 2012. Int. J. Cancer 136, E359-E386. doi: 10.1002/ijc. 29210

Ferret-Sena, V., Capela, C., and Sena, A. (2018). Metabolic dysfunction and peroxisome proliferator-activated receptors (PPAR) in multiple sclerosis. Int. J. Mol. Sci. 19:E1639.

Filipczak-Bryniarska, I., Krzyzewski, R. M., Kucharz, J., MichalowskaKaczmarczyk, A., Kleja, J., Woron, J., et al. (2017). High-dose 8\% capsaicin patch in treatment of chemotherapy-induced peripheral neuropathy: single-center experience. Med. Oncol. 34:162. doi: 10.1007/s12032-017-1015-1

Freitag, C. M., and Miller, R. J. (2014). Peroxisome proliferator-activated receptor agonists modulate neuropathic pain: a link to chemokines? Front. Cell Neurosci. 8:238. doi: $10.3389 /$ fncel.2014.00238

Fukuda, Y., Li, Y., and Segal, R. A. (2017). A mechanistic understanding of axon degeneration in chemotherapy-induced peripheral neuropathy. Front. Neurosci. 11:481. doi: 10.3389/fnins.2017.00481

Gebremedhn, E. G., Shortland, P. J., and Mahns, D. A. (2018). The incidence of acute oxaliplatin-induced neuropathy and its impact on treatment in the first cycle: a systematic review. BMC Cancer 18:410. doi: 10.1186/s12885-0184185-0

Gilchrist, L. S., Tanner, L. R., and Ness, K. K. (2017). Short-term recovery of chemotherapy-induced peripheral neuropathy after treatment for pediatric non-CNS cancer. Pediatr. Blood Cancer 64, 180-187. doi: 10.1002/pbc.26204

Glimelius, B., Manojlovic, N., Pfeiffer, P., Mosidze, B., Kurteva, G., Karlberg, M., et al. (2018). Persistent prevention of oxaliplatin-induced peripheral neuropathy using calmangafodipir (PledOx ${ }^{\circledR}$ ): a placebo-controlled randomised phase II study (PLIANT). Acta Oncol. 57, 393-402. doi: 10.1080/0284186X.2017.1398836

Gong, S. S., Li, Y. X., Zhang, M. T., Du, J., Ma, P. S., Yao, W. X., et al. (2016). Neuroprotective effect of matrine in mouse model of vincristine-induced neuropathic pain. Neurochem. Res. 41, 3147-3159. doi: 10.1007/s11064-0162040-8

Griggs, R. B., Donahue, R. R., Morgenweck, J., Grace, P. M., Sutton, A., Watkins, L. R., et al. (2015). Pioglitazone rapidly reduces neuropathic pain through astrocyte and nongenomic PPARgamma mechanisms. Pain 156, 469-482. doi: 10.1097/01.j.pain.0000460333.79127.be

Guan, Y., and Breyer, M. D. (2001). Peroxisome proliferator-activated receptors (PPARs): novel therapeutic targets in renal disease. Kidney Int. 60, 14-30. doi: 10.1046/j.1523-1755.2001.00766.x

Guimaraes, A. R., Rakhlin, E., Weissleder, R., and Thayer, S. P. (2008). Magnetic resonance imaging monitors physiological changes with antihedgehog therapy in pancreatic adenocarcinoma xenograft model. Pancreas 37, 440-444. doi: 10.1097/MPA.0b013e31817c5113

Guo, Y., Jones, D., Palmer, J. L., Forman, A., Dakhil, S. R., Velasco, M. R., et al. (2014). Oral alpha-lipoic acid to prevent chemotherapy-induced peripheral neuropathy: a randomized, double-blind, placebo-controlled trial. Support. Care Cancer 22, 1223-1231. doi: 10.1007/s00520-013-2075-1

Han, L., Shen, W. J., Bittner, S., Kraemer, F. B., and Azhar, S. (2017). PPARs: regulators of metabolism and as therapeutic targets in cardiovascular disease. Part II: PPAR-beta/delta and PPAR-gamma. Future Cardiol. 13, 279-296. doi: $10.2217 /$ fca-2017-0019

Hanahan, D., and Weinberg, R. A. (2011). Hallmarks of cancer: the next generation. Cell 144, 646-674. doi: 10.1016/j.cell.2011.02.013

Heneka, M. T., and Landreth, G. E. (2007). PPARs in the brain. Biochim. Biophys. Acta 1771, 1031-1045. doi: 10.1016/j.bbalip.2007.04.016

Hershman, D. L., Lacchetti, C., Dworkin, R. H., Lavoie Smith, E. M., Bleeker, J., Cavaletti, G., et al. (2014). Prevention and management of 
chemotherapy-induced peripheral neuropathy in survivors of adult cancers: american society of clinical oncology clinical practice guideline. J. Clin. Oncol. 32, 1941-1967. doi: 10.1200/JCO.2013.54.0914

Hershman, D. L., Unger, J. M., Crew, K. D., Minasian, L. M., Awad, D., Moinpour, C. M., et al. (2013). Randomized double-blind placebo-controlled trial of acetyl-L-carnitine for the prevention of taxane-induced neuropathy in women undergoing adjuvant breast cancer therapy. J. Clin. Oncol. 31, 2627-2633. doi: 10.1200/JCO.2012.44.8738

Hershman, D. L., Weimer, L. H., Wang, A., Kranwinkel, G., Brafman, L., Fuentes, D., et al. (2011). Association between patient reported outcomes and quantitative sensory tests for measuring long-term neurotoxicity in breast cancer survivors treated with adjuvant paclitaxel chemotherapy. Breast Cancer Res. Treat. 125, 767-774. doi: 10.1007/s10549-010-1278-0

Hirayama, Y., Ishitani, K., Sato, Y., Iyama, S., Takada, K., Murase, K., et al. (2015). Effect of duloxetine in Japanese patients with chemotherapy-induced peripheral neuropathy: a pilot randomized trial. Int. J. Clin. Oncol. 20, 866-871. doi: 10.1007/s10147-015-0810-y

Hou, S., Huh, B., Kim, H. K., Kim, K. H., and Abdi, S. (2018). Treatment of chemotherapy-induced peripheral neuropathy: systematic review and recommendations. Pain Physician 21, 571-592.

Hua, T. N. M., Kim, M. K., Vo, V. T. A., Choi, J. W., Choi, J. H., Kim, H. W., et al. (2019). Inhibition of oncogenic Src induces FABP4-mediated lipolysis via PPARgamma activation exerting cancer growth suppression. EBioMedicine 41, 134-145. doi: 10.1016/j.ebiom.2019.02.015

Hunter, R. L., Dragicevic, N., Seifert, K., Choi, D. Y., Liu, M., Kim, H. C., et al. (2007). Inflammation induces mitochondrial dysfunction and dopaminergic neurodegeneration in the nigrostriatal system. J. Neurochem. 100, 1375-1386. doi: 10.1111/j.1471-4159.2006.04327.x

Issemann, I., and Green, S. (1990). Activation of a member of the steroid hormone receptor superfamily by peroxisome proliferators. Nature 347, 645-650. doi: 10.1038/347645a0

Itoh, T., Fairall, L., Amin, K., Inaba, Y., Szanto, A., Balint, B. L., et al. (2008). Structural basis for the activation of PPARgamma by oxidized fatty acids. Nat. Struct. Mol. Biol. 15, 924-931. doi: 10.1038/nsmb.1474

Jain, V., Jaggi, A. S., and Singh, N. (2009). Ameliorative potential of rosiglitazone in tibial and sural nerve transection-induced painful neuropathy in rats. Pharmacol. Res. 59, 385-392. doi: 10.1016/j.phrs.2009.02.001

Janes, K., Doyle, T., Bryant, L., Esposito, E., Cuzzocrea, S., Ryerse, J., et al. (2013). Bioenergetic deficits in peripheral nerve sensory axons during chemotherapyinduced neuropathic pain resulting from peroxynitrite-mediated posttranslational nitration of mitochondrial superoxide dismutase. Pain 154, 2432-2440. doi: 10.1016/j.pain.2013.07.032

Janes, K., Wahlman, C., Little, J. W., Doyle, T., Tosh, D. K., Jacobson, K. A., et al. (2015). Spinal neuroimmune activation is independent of T-cell infiltration and attenuated by $\mathrm{A} 3$ adenosine receptor agonists in a model of oxaliplatin-induced peripheral neuropathy. Brain Behav. Immun. 44, 91-99. doi: 10.1016/j.bbi.2014. 08.010

Ji, X. T., Qian, N. S., Zhang, T., Li, J. M., Li, X. K., Wang, P., et al. (2013). Spinal astrocytic activation contributes to mechanical allodynia in a rat chemotherapyinduced neuropathic pain model. PLoS One 8:e60733. doi: 10.1371/journal. pone. 0060733

Jia, H. B., Wang, X. M., Qiu, L. L., Liu, X. Y., Shen, J. C., Ji, Q., et al. (2013). Spinal neuroimmune activation inhibited by repeated administration of pioglitazone in rats after L5 spinal nerve transection. Neurosci. Lett. 543, 130-135. doi: 10.1016/j.neulet.2013.03.046

Jin, J., Albertz, J., Guo, Z., Peng, Q., Rudow, G., Troncoso, J. C., et al. (2013). Neuroprotective effects of PPAR-gamma agonist rosiglitazone in N171-82Q mouse model of Huntington's disease. J. Neurochem. 125, 410-419. doi: 10. $1111 /$ jnc. 12190

Jordan, M. A., and Wilson, L. (2004). Microtubules as a target for anticancer drugs. Nat. Rev. Cancer 4, 253-265. doi: 10.1038/nrc1317

Jung, Y., and Lippard, S. J. (2007). Direct cellular responses to platinum-induced DNA damage. Chem. Rev. 107, 1387-1407. doi: 10.1021/cr068207j

Kainu, T., Wikstrom, A. C., Gustafsson, J. A., and Pelto-Huikko, M. (1994). Localization of the peroxisome proliferator-activated receptor in the brain. Neuroreport 5, 2481-2485.

Kautio, A. L., Haanpaa, M., Saarto, T., and Kalso, E. (2008). Amitriptyline in the treatment of chemotherapy-induced neuropathic symptoms.
J. Pain Symptom Manage. 35, 31-39. doi: 10.1016/j.jpainsymman.2007. 02.043

Kerckhove, N., Collin, A., Conde, S., Chaleteix, C., Pezet, D., Balayssac, D., et al. (2018). [Chemotherapy-induced peripheral neuropathy: symptomatology and epidemiology]. Bull. Cancer 105, 1020-1032. doi: 10.1016/j.bulcan.2018. 07.009

Khasabova, I. A., Khasabov, S. G., Olson, J. K., Uhelski, M. L., Kim, A. H., AlbinoRamirez, A. M., et al. (2019). Pioglitazone, a PPARgamma agonist, reduces cisplatin-evoked neuropathic pain by protecting against oxidative stress. Pain 160, 688-701. doi: 10.1097/j.pain.0000000000001448

Korbecki, J., Bobinski, R., and Dutka, M. (2019). Self-regulation of the inflammatory response by peroxisome proliferator-activated receptors. Inflamm. Res. 68, 443-458. doi: 10.1007/s00011-019-01231-1

Kottschade, L. A., Sloan, J. A., Mazurczak, M. A., Johnson, D. B., Murphy, B. P., Rowland, K.M., et al. (2011). The use of vitamin E for the prevention of chemotherapy-induced peripheral neuropathy: results of a randomized phase III clinical trial. Support Care Cancer. 19, 1769-1777. doi: 10.1007/s00520-0101018-3

Lapointe, N. E., Morfini, G., Brady, S. T., Feinstein, S. C., Wilson, L., and Jordan, M. A. (2013). Effects of eribulin, vincristine, paclitaxel and ixabepilone on fast axonal transport and kinesin-1 driven microtubule gliding: implications for chemotherapy-induced peripheral neuropathy. Neurotoxicology 37, 231-239. doi: 10.1016/j.neuro.2013.05.008

Leal, A. D., Qin, R., Atherton, P. J., Haluska, P., Behrens, R. J., Tiber, C. H., et al. (2014). North central cancer treatment group/alliance trial N08CA-the use of glutathione for prevention of paclitaxel/carboplatin-induced peripheral neuropathy: a phase 3 randomized, double-blind, placebo-controlled study. Cancer 120, 1890-1897. doi: 10.1002/cncr.28654

Liu, H. J., and Fang, H. S. (1983). Influence of severe decompression on peripheral vascular beds. Taiwan Yi Xue Hui Za Zhi 82, 1229-1232.

Lu, M., Sarruf, D. A., Talukdar, S., Sharma, S., Li, P., Bandyopadhyay, G., et al. (2011). Brain PPAR-gamma promotes obesity and is required for the insulinsensitizing effect of thiazolidinediones. Nat. Med. 17, 618-622. doi: 10.1038/nm. 2332

Luconi, M., Cantini, G., and Serio, M. (2010). Peroxisome proliferator-activated receptor gamma (PPARgamma): is the genomic activity the only answer? Steroids 75, 585-594. doi: 10.1016/j.steroids.2009.10.012

Lv, S., Wang, W., Wang, H., Zhu, Y., and Lei, C. (2019). PPARgamma activation serves as therapeutic strategy against bladder cancer via inhibiting PI3K-Akt signaling pathway. BMC Cancer 19:204. doi: 10.1186/s12885-019-5426-6

Lynch, M. E., Cesar-Rittenberg, P., and Hohmann, A. G. (2014). A double-blind, placebo-controlled, crossover pilot trial with extension using an oral mucosal cannabinoid extract for treatment of chemotherapy-induced neuropathic pain. J. Pain Symptom Manage. 47, 166-173. doi: 10.1016/j.jpainsymman.2013. 02.018

Lyons, D. N., Zhang, L., Danaher, R. J., Miller, C. S., and Westlund, K. N. (2017). PPARgamma agonists attenuate trigeminal neuropathic pain. Clin. J. Pain 33, 1071-1080. doi: 10.1097/AJP.0000000000000509

Ma, Y., Wang, B., Li, L., Wang, F., and Xia, X. (2019). The administration of peroxisome proliferator-activated receptors alpha/gamma agonist TZD18 inhibits cell growth and induces apoptosis in human gastric cancer cell lines. J. Cancer Res. Ther. 15, 120-125. doi: 10.4103/0973-1482.208753

Maeda, T., Kiguchi, N., Kobayashi, Y., Ozaki, M., and Kishioka, S. (2008). Pioglitazone attenuates tactile allodynia and thermal hyperalgesia in mice subjected to peripheral nerve injury. J. Pharmacol. Sci. 108, 341-347. doi: 10.1254/jphs.08207fp

Maeda, T., and Kishioka, S. (2009). PPAR and pain. Int. Rev. Neurobiol. 85, 165-177. doi: 10.1016/s0074-7742(09)85013-7

Makker, P. G., Duffy, S. S., Lees, J. G., Perera, C. J., Tonkin, R. S., Butovsky, O., et al. (2017). Characterisation of immune and neuroinflammatory changes associated with chemotherapy-induced peripheral neuropathy. PLoS One 12:e0170814. doi: 10.1371/journal.pone.0170814

Malik, S., Suchal, K., Bhatia, J., Khan, S. I., Vasisth, S., Tomar, A., et al. (2016). Therapeutic potential and molecular mechanisms of emblica officinalis gaertn in countering nephrotoxicity in rats induced by the chemotherapeutic agent cisplatin. Front. Pharmacol. 7:350. doi: 10.3389/fphar.2016.00350

Manjavachi, M. N., Passos, G. F., Trevisan, G., Araujo, S. B., Pontes, J. P., Fernandes, E. S., et al. (2019). Spinal blockage of CXCL1 and its receptor CXCR2 
inhibits paclitaxel-induced peripheral neuropathy in mice. Neuropharmacology 151, 136-143. doi: 10.1016/j.neuropharm.2019.04.014

Marotta, D. M., Costa, R., Motta, E. M., Fernandes, E. S., Medeiros, R., Quintão, N. L., et al. (2009). Mechanisms underlying the nociceptive responses induced by platelet-activating factor (PAF) in the rat paw. Biochem. Pharmacol. 77, 1223-1235. doi: 10.1016/j.bcp.2008.12.025

Martin, N. A., Cruz-Pacheco, G., and Mancera, P. F. (2015a). Um modelo matemático de câncer com quimioterapia e imunoterapia. Proc. Ser. Braz. Soc. Comput. Appl. Math. 3, 1-6. doi: 10.5540/03.2015.003.01.0046

Martin, E., Morel, V., Joly, D., Villatte, C., Delage, N., Dubray, C., et al. (2015b). Rationale and design of a randomized double-blind clinical trial in breast cancer: dextromethorphan in chemotherapy-induced peripheral neuropathy. Contemp. Clin. Trials 41, 146-151. doi: 10.1016/j.cct.2015.01.012

Masure, O., Bayon, A. M., Chastel, C., and Bergeret, G. (1983). [Peritoneal cryptococcosis: discussion of clinical facts]. Bull. Soc. Pathol. Exot. Filiales 76, 346-350.

Matsuoka, H., Ishiki, H., Iwase, S., Koyama, A., Kawaguchi, T., Kizawa, Y., et al. (2017). Study protocol for a multi-institutional, randomised, double-blinded, placebo-controlled phase III trial investigating additive efficacy of duloxetine for neuropathic cancer pain refractory to opioids and gabapentinoids: the DIRECT study. BMJ Open 7:e017280. doi: 10.1136/bmjopen-2017-017280

Miglio, G., Rosa, A. C., Rattazzi, L., Collino, M., Lombardi, G., and Fantozzi, R. (2009). PPARgamma stimulation promotes mitochondrial biogenesis and prevents glucose deprivation-induced neuronal cell loss. Neurochem. Int. 55, 496-504. doi: 10.1016/j.neuint.2009.05.001

Mihara, Y., Egashira, N., Sada, H., Kawashiri, T., Ushio, S., Yano, T., et al. (2011). Involvement of spinal NR2B-containing NMDA receptors in oxaliplatininduced mechanical allodynia in rats. Mol. Pain 7:8. doi: 10.1186/17448069-7-8

Miltenburg, N. C., and Boogerd, W. (2014). Chemotherapy-induced neuropathy: a comprehensive survey. Cancer Treat. Rev. 40, 872-882. doi: 10.1016/j.ctrv.2014. 04.004

Molassiotis, A., Cheng, H. L., Lopez, V., Au, J. S. K., Chan, A., Bandla, A., et al. (2019). Are we mis-estimating chemotherapy-induced peripheral neuropathy? analysis of assessment methodologies from a prospective, multinational, longitudinal cohort study of patients receiving neurotoxic chemotherapy. BMC Cancer 19:132. doi: 10.1186/s12885-019-5302-4

Moreno, S., Farioli-Vecchioli, S., and Ceru, M. P. (2004). Immunolocalization of peroxisome proliferator-activated receptors and retinoid $\mathrm{X}$ receptors in the adult rat CNS. Neuroscience 123, 131-145. doi: 10.1016/j.neuroscience.2003. 08.064

Moress, G. R., D’agostino, A. N., and Jarcho, L. W. (1967). Neuropathy in lymphoblastic leukemia treated with vincristine. Arch. Neurol. 16, 377-384. doi: 10.1001/archneur.1967.00470220041005

Morgenweck, J., Griggs, R. B., Donahue, R. R., Zadina, J. E., and Taylor, B. K. (2013). PPARgamma activation blocks development and reduces established neuropathic pain in rats. Neuropharmacology 70, 236-246. doi: 10.1016/j. neuropharm.2013.01.020

Neves, A. P., and Vargas, M. D. (2011). Complexos de platina(II) na terapia do câncer. Rev. Virtual Quim. 3, 196-209.

Nurgali, K., Jagoe, R. T., and Abalo, R. (2018). Editorial: adverse effects of cancer chemotherapy: anything new to improve tolerance and reduce sequelae? Front. Pharmacol. 9:245. doi: 10.3389/fphar.2018.00245

Okine, B. N., Gaspar, J. C., and Finn, D. P. (2019). PPARs and pain. Br. J. Pharmacol. 176, 1421-1442. doi: 10.1111/bph.14339

Pachman, D. R., Dockter, T., Zekan, P. J., Fruth, B., Ruddy, K. J., Ta, L. E., et al. (2017). A pilot study of minocycline for the prevention of paclitaxel-associated neuropathy: ACCRU study RU221408I. Support. Care Cancer 25, 3407-3416. doi: 10.1007/s00520-017-3760-2

Park, S. W., Yi, J. H., Miranpuri, G., Satriotomo, I., Bowen, K., Resnick, D. K., et al. (2007). Thiazolidinedione class of peroxisome proliferator-activated receptor gamma agonists prevents neuronal damage, motor dysfunction, myelin loss, neuropathic pain, and inflammation after spinal cord injury in adult rats. J. Pharmacol. Exp. Ther. 320, 1002-1012. doi: 10.1124/jpet.106.113472

Pascual, D., Goicoechea, C., Burgos, E., and Martin, M. I. (2010). Antinociceptive effect of three common analgesic drugs on peripheral neuropathy induced by paclitaxel in rats. Pharmacol. Biochem. Behav. 95, 331-337. doi: 10.1016/j.pbb. 2010.02.009
Pasetto, L. M., D’andrea, M. R., Brandes, A. A., Rossi, E., and Monfardini, S. (2006). The development of platinum compounds and their possible combination. Crit. Rev. Oncol. Hematol. 60, 59-75. doi: 10.1016/j.critrevonc.2006. 02.003

Patel, S. P., Cox, D. H., Gollihue, J. L., Bailey, W. M., Geldenhuys, W. J., Gensel, J. C., et al. (2017). Pioglitazone treatment following spinal cord injury maintains acute mitochondrial integrity and increases chronic tissue sparing and functional recovery. Exp. Neurol. 293, 74-82. doi: 10.1016/j.expneurol. 2017.03.021

Pawlak, M., Lefebvre, P., and Staels, B. (2012). General molecular biology and architecture of nuclear receptors. Curr. Top. Med. Chem. 12, 486-504. doi: $10.2174 / 156802612799436641$

Perez-Herrero, E., and Fernandez-Medarde, A. (2015). Advanced targeted therapies in cancer: drug nanocarriers, the future of chemotherapy. Eur. J. Pharm. Biopharm. 93, 52-79. doi: 10.1016/j.ejpb.2015. 03.018

Piccinin, E., Villani, G., and Moschetta, A. (2019). Metabolic aspects in NAFLD, NASH and hepatocellular carcinoma: the role of PGC1 coactivators. Nat. Rev. Gastroenterol. Hepatol. 16, 160-174. doi: 10.1038/s41575-018-0089-3

Pottabathini, R., Kumar, A., Bhatnagar, A., Garg, S., and Ekavali, E. (2016). Ameliorative potential of pioglitazone and ceftriaxone alone and in combination in rat model of neuropathic pain: targeting PPARgamma and GLT-1 pathways. Pharmacol. Rep. 68, 85-94. doi: 10.1016/j.pharep.2015.06.010

Rao, R. D., Flynn, P. J., Sloan, J. A., Wong, G. Y., Novotny, P., Johnson, D. B., et al. (2008). Efficacy of lamotrigine in the management of chemotherapy-induced peripheral neuropathy: a phase 3 randomized, double-blind, placebo-controlled trial, N01C3. Cancer 112, 2802-2808. doi: 10.1002/cncr.23482

Rao, R. D., Michalak, J. C., Sloan, J. A., Loprinzi, C. L., Soori, G. S., Nikcevich, D. A., et al. (2007). Efficacy of gabapentin in the management of chemotherapyinduced peripheral neuropathy: a phase 3 randomized, double-blind, placebocontrolled, crossover trial (N00C3). Cancer 110, 2110-2118. doi: 10.1002/cncr. 23008

Rochel, N., Krucker, C., Coutos-Thevenot, L., Osz, J., Zhang, R., Guyon, E., et al. (2019). Recurrent activating mutations of PPARgamma associated with luminal bladder tumors. Nat. Commun. 10:253. doi: 10.1038/s41467-018-08157-y

Sapunar, D., Kostic, S., Banozic, A., and Puljak, L. (2012). Dorsal root ganglion a potential new therapeutic target for neuropathic pain. J. Pain Res. 5, 31-38. doi: $10.2147 /$ JPR.S26603

Sauer, S. (2015). Ligands for the nuclear peroxisome proliferator-activated receptor gamma. Trends Pharmacol. Sci. 36, 688-704. doi: 10.1016/j.tips.2015.06.010

Segat, G. C., Manjavachi, M. N., Matias, D. O., Passos, G. F., Freitas, C. S., Costa, R., et al. (2017). Antiallodynic effect of beta-caryophyllene on paclitaxel-induced peripheral neuropathy in mice. Neuropharmacology 125, 207-219. doi: 10.1016/ j.neuropharm.2017.07.015

Seiri, P., Abi, A., and Soukhtanloo, M. (2019). PPAR-gamma: its ligand and its regulation by microRNAs. J. Cell Biochem. 120, 10893-10908. doi: 10.1002/jcb. 28419

Shao, D., Rangwala, S. M., Bailey, S. T., Krakow, S. L., Reginato, M. J., and Lazar, M. A. (1998). Interdomain communication regulating ligand binding by PPAR-gamma. Nature 396, 377-380. doi: 10.1038/24634

Shinde, S. S., Seisler, D., Soori, G., Atherton, P. J., Pachman, D. R., Lafky, J., et al. (2016). Can pregabalin prevent paclitaxel-associated neuropathy?-An ACCRU pilot trial. Support. Care Cancer 24, 547-553. doi: 10.1007/s00520-015-2807-5

Sisignano, M., Baron, R., Scholich, K., and Geisslinger, G. (2014). Mechanismbased treatment for chemotherapy-induced peripheral neuropathic pain. Nat. Rev. Neurol. 10, 694-707. doi: 10.1038/nrneurol.2014.211

Smith, E. M., Pang, H., Cirrincione, C., Fleishman, S., Paskett, E. D., Ahles, T., et al. (2013). Effect of duloxetine on pain, function, and quality of life among patients with chemotherapy-induced painful peripheral neuropathy: a randomized clinical trial. JAMA 309, 1359-1367. doi: 10.1001/jama.2013.2813

Smith, E. M., Pang, H., Ye, C., Cirrincione, C., Fleishman, S., Paskett, E. D., et al. (2017). Predictors of duloxetine response in patients with oxaliplatin-induced painful chemotherapy-induced peripheral neuropathy (CIPN): a secondary analysis of randomised controlled trial - CALGB/alliance 170601. Eur. J. Cancer Care 26:e12421. doi: 10.1111/ecc.12421

Starobova, H., and Vetter, I. (2017). Pathophysiology of chemotherapy-induced peripheral neuropathy. Front. Mol. Neurosci. 10:174. doi: 10.3389/fnmol.2017. 00174 
Swanson, C. R., Du, E., Johnson, D. A., Johnson, J. A., and Emborg, M. E. (2013). Neuroprotective properties of a novel non-thiazoledinedione partial PPARgamma agonist against MPTP. PPAR Res. 2013:582809. doi: 10.1155/2013/ 582809

Takahashi, Y., Hasegawa-Moriyama, M., Sakurai, T., and Inada, E. (2011). The macrophage-mediated effects of the peroxisome proliferator-activated receptorgamma agonist rosiglitazone attenuate tactile allodynia in the early phase of neuropathic pain development. Anesth. Analg. 113, 398-404. doi: 10.1213/ANE. 0b013e31821b220c

Torre, L. A., Bray, F., Siegel, R. L., Ferlay, J., Lortet-Tieulent, J., and Jemal, A. (2015). Global cancer statistics, 2012. CA Cancer J. Clin. 65, 87-108. doi: 10.3322/caac. 21262

Toyama, S., Naohito, S., Hazel, H. S., Peter, W. S., and Megumi, S. (2018). Protective effect of a mitochondria-targeted peptide against the development of chemotherapy-induced peripheral neuropathy in mice. ACS Chem. Neurosci. 9, 1566-1571. doi: 10.1021/acschemneuro.8b00013

Trecarichi, A., and Flatters, S. J. L. (2019). Mitochondrial dysfunction in the pathogenesis of chemotherapy-induced peripheral neuropathy. Int. Rev. Neurobiol. 145, 83-126. doi: 10.1016/bs.irn.2019.05.001

Vallee, A., and Lecarpentier, Y. (2016). Alzheimer disease: crosstalk between the canonical Wnt/Beta-catenin pathway and PPARs alpha and gamma. Front. Neurosci. 10:459. doi: 10.3389/fnins.2016.00459

Van Beekum, O., Fleskens, V., and Kalkhoven, E. (2009). Posttranslational modifications of PPAR-gamma: fine-tuning the metabolic master regulator. Obesity 17, 213-219. doi: 10.1038/oby.2008.473

Vashistha, B., Sharma, A., and Jain, V. (2017). Ameliorative potential of ferulic acid in vincristine-induced painful neuropathy in rats: an evidence of behavioral and biochemical examination. Nutr. Neurosci. 20, 60-70. doi: 10.1179/ 1476830514Y.0000000165

Villapol, S. (2018). Roles of peroxisome proliferator-activated receptor gamma on brain and peripheral inflammation. Cell Mol. Neurobiol. 38, 121-132. doi: 10.1007/s10571-017-0554-5

Waldmann, T. A. (2003). Immunotherapy: past, present and future. Nat. Med. 9, 269-277.

Wang, X., Wang, Z., Liu, J. Z., Hu, J. X., Chen, H. L., Li, W. L., et al. (2011). Double antioxidant activities of rosiglitazone against high glucose-induced oxidative stress in hepatocyte. Toxicol. In Vitro 25, 839-847. doi: 10.1016/j.tiv.2011. 02.004

Warden, A., Truitt, J., Merriman, M., Ponomareva, O., Jameson, K., Ferguson, L. B., et al. (2016). Localization of PPAR isotypes in the adult mouse and human brain. Sci. Rep. 6:27618. doi: 10.1038/srep27618

Weaver, B. A. (2014). How taxol/paclitaxel kills cancer cells. Mol. Biol. Cell 25, 2677-2681. doi: 10.1091/mbc.E14-04-0916

Wheate, N. J., Walker, S., Craig, G. E., and Oun, R. (2010). The status of platinum anticancer drugs in the clinic and in clinical trials. Dalton Trans. 39, 8113-8127. doi: $10.1039 / \mathrm{c0dt} 00292 \mathrm{e}$
Winters-Stone, K. M., Horak, F., Jacobs, P. G., Trubowitz, P., Dieckmann, N. F., Stoyles, S., et al. (2017). Falls, functioning, and disability among women with persistent symptoms of chemotherapy-induced peripheral neuropathy. J. Clin. Oncol. 35, 2604-2612. doi: 10.1200/JCO.2016.71.3552

Wolff, C., Zoschke, C., Kumar Kalangi, S., Reddanna, P., and Schafer-Korting, M. (2019). Tumor microenvironment determines drug efficacy in vitro - apoptotic and anti-inflammatory effects of 15-lipoxygenase metabolite, 13-HpOTrE. Eur. J. Pharm. Biopharm. 142, 1-7. doi: 10.1016/j.ejpb.2019.06.003

Wu, Y., Song, T., Liu, M., He, Q., Chen, L., Liu, Y., et al. (2019). PPARG negatively modulates Six 2 in tumor formation of clear cell renal cell carcinoma. DNA Cell Biol. 38, 700-707. doi: 10.1089/dna.2018.4549

Xochilcal-Morales, M., Castro, E. M., Guajardo-Rosas, J., Obregon, T. N., Acevedo, J. C., Chucan, J. M., et al. (2010). A prospective, open-label, multicentre study of pregabalin in the treatment of neuropathic pain in latin america. Int. J. Clin. Pract. 64, 1301-1309. doi: 10.1111/j.1742-1241.2010.02389.x

Zajaczkowska, R., Kocot-Kepska, M., Leppert, W., Wrzosek, A., Mika, J., and Wordliczek, J. (2019). Mechanisms of chemotherapy-induced peripheral neuropathy. Int. J. Mol. Sci. 20:E1451. doi: 10.3390/ijms20061451

Zanardelli, M., Micheli, L., Cinci, L., Failli, P., Ghelardini, C., and Di Cesare Mannelli, L. (2014). Oxaliplatin neurotoxicity involves peroxisome alterations. PPARgamma agonism as preventive pharmacological approach. PLoS One 9:e102758. doi: 10.1371/journal.pone.0102758

Zhao, D., Ma, Y., Li, X., and Lu, X. (2019). microRNA-211 promotes invasion and migration of colorectal cancer cells by targeting FABP4 via PPARgamma. J. Cell Physiol. doi: 10.1002/jcp.28190 [Epub ahead of print].

Zhou, Y. Q., Liu, D. Q., Chen, S. P., Sun, J., Zhou, X. R., Rittner, H., et al. (2018). Reactive oxygen species scavengers ameliorate mechanical allodynia in a rat model of cancer-induced bone pain. Redox Biol. 14, 391-397. doi: 10.1016/j. redox.2017.10.011

Zolezzi, J. M., Silva-Alvarez, C., Ordenes, D., Godoy, J. A., Carvajal, F. J., Santos, M. J., et al. (2013). Peroxisome proliferator-activated receptor (PPAR) gamma and PPARalpha agonists modulate mitochondrial fusion-fission dynamics: relevance to reactive oxygen species (ROS)-related neurodegenerative disorders? PLoS One 8:e64019. doi: 10.1371/journal.pone.0064019

Conflict of Interest Statement: The authors declare that the research was conducted in the absence of any commercial or financial relationships that could be construed as a potential conflict of interest.

Copyright (c) 2019 Quintão, Santin, Stoeberl, Corrêa, Melato and Costa. This is an open-access article distributed under the terms of the Creative Commons Attribution License (CC BY). The use, distribution or reproduction in other forums is permitted, provided the original author(s) and the copyright owner(s) are credited and that the original publication in this journal is cited, in accordance with accepted academic practice. No use, distribution or reproduction is permitted which does not comply with these terms. 